\title{
Measurements of the Thermal Conductivity and Electrical Resistivity of Platinum from 100 to $900{ }^{\circ} \mathrm{C}^{*}$
}

\author{
D. R. Flynn and M. E. O'Hagan** \\ Institute for Applied Technology, National Bureau of Standards, Washington, D.C. 20234
}

(August 17, 1967)

\section{Introduction}

Standards and standard reference materials are the basis of a consistent and accurate measuring system. The need for standard reference materials in thermal conductivity measurements is two-fold. In the first place, such materials are required for comparative measurements in which the thermal conductivity of the material under test is determined in terms of that of the standard reference material. Secondly, such materials are required in evaluating the accuracy of apparatus designed for thermal conductivity measurements. The degree to which the measured value of the thermal conductivity of the standard reference material agrees with the accepted value is a check on the accuracy of the apparatus in which the measurements were made.

The basic requirements for any standard reference material are that it be stable, reproducible and appropriate for the measurements at hand, and that the property in question be uniform throughout the material. In the case of standard reference materials for thermal conductivity other desirable requirements are that the standard be usable over a wide range of temperature, that it be chemically inert so as not to be

\footnotetext{
*This research was the subject of a dissertation submitted by M. E. O'Hagan to the Faculty of The School of Engineering and Applied Science, The George Washington University, in partial satisfaction of the requirements for the degree of Doctor of Science. This work was supported in part by Engelhard Industries, Inc., Newark, New Jersey, who supplied the platinum and financial assistance in the form of a grant to the National Bureau of Standards. M. E. O'Hagan was supported in part by Grant AFOSR-1025-66 from the Air Force Office of Scientific Research and in part by the Institute for Industrial Research and Standards, Dublin, Ireland.
}

affected by or affect other materials in the system and that the thermal conductivity of the reference material be close in value to that of the materials which are to be measured in terms of it.

The advantages of using platinum as a thermal conductivity reference material have been pointed out by Powell and Tye [1] and by Slack [2]. Platinum is available in high purity in pieces of substantial size. It has a fairly high melting point $\left(1769{ }^{\circ} \mathrm{C}\right.$ on the 1948 International Practical Temperature Scale), has no known transition points, and is relatively stable chemically in air and other atmospheres, with the exception of hydrogen, even at high temperatures [3, 4]. Its thermal conductivity, although relatively high for use as a reference material with nonmetals, is about the geometric mean for metals and alloys.

Since the thermal conductivity of a pure metal is strongly correlated with the electrical conductivity of the metal, it is highly desirable that the electrical conductivity of a metal which is intended for use as a thermal conductivity reference material be very stable under varying heat treatments. The stability of the electrical conductivity of platinum is evidenced by the fact that the International Practical Temperature Scale is defined by a platinum resistance thermometer in the temperature range -182.97 to $+630.5^{\circ} \mathrm{C}[5,6]$. Studies are currently underway at NBS [7] and other laboratories to investigate the possibility of extending to the gold-point $\left(1063{ }^{\circ} \mathrm{C}\right)$ the range over which a platinum resistance thermometer is used to define the temperature scale.

\footnotetext{
' Fiqures in brackets indicate the literature references at the end of this paper.
} 
Platinum appears to be, in every way save one, an ideal material to use as a thermal conductivity reference standard. The exception is that the spread among the literature values for the thermal conductivity of platinum is considerable, to say the least.

Powell, Ho, and Liley [8] show a plot of essentially all of the published thermal conductivity data for platinum through the year 1965. The spread in the data increases from about 10 percent at room temperature to over 30 percent at $1000{ }^{\circ} \mathrm{C}$. Even if many of the older data are discounted, the picture is not particularly improved. O'Hagan [9] has summarized the methods used for previous measurements of the thermal conductivity of platinum and also has summarized the characterizations of the various samples.

Prior to the measurements of Powell and Tye [1], all thermal conductivity values reported for platinum at temperatures above $100{ }^{\circ} \mathrm{C}$ were obtained by methods in which the temperature gradient in the specimen was produced by Joule heating due to passage of an electric current directly through the specimen. While the results of all but one [10] of these higher temperature investigations employing electrical methods essentially agree with one another, they disagree with those of later investigations $[1,11,12]$, which employed nonelectrical methods. This raised the question as to whether or not electrical methods yield results that are intrinsically different from those of nonelectrical methods. This could mean that the theory which has been used in analyzing electrical methods is in error, or it could mean that heat conduction is significantly dependent on electric current density, at least in the case of platinum.

The considerations discussed above pointed to the need for a comprehensive investigation of the thermal conductivity of platinum. It was felt that both an absolute steady-state method without an electric current flowing in the specimen, and also an absolute steady-state method with a current flowing in the specimen should be employed.

As regards the nonelectrical method, experience at NBS with guarded longitudinal heat flow methods indicated that such a method could be made to yield accurate results on a material having as high a thermal conductivity as platinum, provided a specimen of sufficient cross-sectional area was used. With a fairly conductive metal, there were no particular advantages in going to a radial heat flow method; furthermore, to do so would have required a much larger sample.

As regards the electrical method, an arrangement utilizing quite large current densities would be more likely to reveal deviations due to a dependence of thermal conductivity on current density. It was also desirable to use the same method as that used by most of the previous investigators. Fortunately, these two desiderata both pointed to the necked-down sample configuration utilized for measurements on platinum by Holm and Störmer [13], by Hopkins [14], and by Cutler, et al. [15].

To give a direct and accurate comparison between the two methods it was considered desirable to combine both sets of measurements in one apparatus and on the same specimen thereby eliminating a number of uncertainties which would arise in comparing data derived from measurements in different apparatus and on different specimens. The above considerations led to an apparatus, described in section 3, in which thermal conductivity measurements can be made by both the usual longitudinal heat flow method and by an electrical method.

It was also felt that thermal conductivity measurements should be made on platinum samples of at least two purities. Samples were obtained of a high purity platinum (resistance thermometer grade) and of a somewhat lower purity platinum (commercial grade). As of this writing, only the measurements on the lower purity platinum sample have been completed. The results obtained on that sample are presented in this paper and are compared with the results of other investigators.

\section{Description of Sample}

In order for a valid comparison to be made between the results of different investigators who measure on a particular kind of material, it is necessary that their specimens be characterized as extensively as possible so that differences in specimens may be accounted for. For this reason a number of pertinent measurements were made in an attempt to characterize the specimen used in the present investigation. These measurements and the results thereof are described below.

The platinum was provided by Englehard Industries, Inc., in the form of a solid bar $2.04 \mathrm{~cm}$ in diameter by $31 \mathrm{~cm}$ long, and was classified as being of commercial purity. The fabrication and cleaning procedures used in preparing the platinum have been described by O'Hagan [9].

The as-received bar was annealed in air for $5.5 \mathrm{hr}$ at $770{ }^{\circ} \mathrm{C}$ in a horizontal tubular furnace and furnace cooled at a rate of approximately $120 \mathrm{deg} / \mathrm{hr}$. Shortly thereafter the bar was accidentally dropped causing it to deform slightly at one end. After correcting the damage the bar was reannealed for $1.5 \mathrm{hr}$ at $680{ }^{\circ} \mathrm{C}$ and furnace cooled at a rate of approximately $90 \mathrm{deg} / \mathrm{hr}$. Its thermal conductivity was then measured in the NBS Metals Apparatus [34, 35] over the temperature range -160 to $+810{ }^{\circ} \mathrm{C}[32]$.

Following these measurements the bar was machined and ground to $25.4 \mathrm{~cm}$ long by $2.000 \mathrm{~cm}$ diam. The density of this bar was measured (see below) and the electrical resistance was measured at ice and liquid helium temperatures (see below). The thermal conductivity specimen $(18.4 \mathrm{~cm}$ long by $2.000 \mathrm{~cm} \mathrm{diam)} \mathrm{was} \mathrm{then} \mathrm{fabricated} \mathrm{from} \mathrm{one} \mathrm{end} \mathrm{of}$ this bar. A length of $6.4 \mathrm{~cm}$ was cut from the other end for separate low temperature thermal conductivity measurements [33]. The remaining disk, approximately $1 \mathrm{~cm}$ long, was reserved for metallographic and spectrographic analyses.

A thin neck, approximately $0.1 \mathrm{~cm}$ in diameter and $0.3 \mathrm{~cm}$ long, was machined in the thermal conductivity specimen at approximately $4 \mathrm{~cm}$ from one end. To cleanse this necked-down region of oil and any con- 
tamination contracted from the cutting tools, the following cleaning procedure was followed. Degreasing was effected by immersion for half an hour in trichlorethylene vapor. The neck was then pickled for $10 \mathrm{~min}$ in hot 50 percent nitric acid. Following this the neck was washed in distilled water, pickled for $10 \mathrm{~min}$ in 50 percent hot hydrochloric acid, and again washed in distilled water. There was equal likelihood of the rest of the specimen having slight surface contamination as a result of machining but its effect on the bulk properties of the specimen would not be nearly as grave as the corresponding effect in the neck region. It was considered sufficient to clean the surface of the specimen with toluene and carbon tetrachloride.

A general qualitative spectrographic analysis, performed by the NBS Spectrochemical Analysis Section on the 2-cm-diam by 1-cm-long platinum disk mentioned above, detected Ag (10-100 ppm), Pd (10-100 ppm), Fe (<10 ppm), and $\mathrm{Mg}(<10 \mathrm{ppm})$. O'Hagan [9] reported the results of a quantitative spectrographic analysis made on a portion of a $0.05 \mathrm{~cm}$ wire drawn from the same platinum ingot as the thermal conductivity specimen.

Photomicrographs were also made of the platinum disk cut from the bar sample. They showed grain size to be of the order of $0.02 \mathrm{~cm}$. No evidence appeared of inclusions of foreign matter or of any irregularities in microstructure. Hardness measurements were made on the original platinum bar, after the second anneal, using a Vickers Pyramidal Diamond Tester with a $10 \mathrm{~kg}$ load. Values ranged from 36.5 to 38.0 Vickers hardness number.

The density of the bar, when it was $25.4 \mathrm{~cm}$ long, was determined by mass and dimensional measurements to be $21.384 \mathrm{~g} / \mathrm{cm}^{3}$ at $21^{\circ} \mathrm{C}$, accurate to within $\pm 0.002 \mathrm{~g} / \mathrm{cm}^{3}$. This density is an average value for the whole bar and there is no guarantee that the density was uniform to that degree throughout the bar.

The ratio of the resistance at the ice-point temperature to that at the boiling point of helium at atmospheric pressure is a measure of the extent and condition of impurities in a material and of the crystallographic state of the material. This ratio was determined on the 2-cm-diam bar.

The ice-point resistances were measured both before and after the helium point measurements. The current was supplied from a regulated d-c power supply and was measured using a calibrated resistor and a precision potentiometer. The voltage drops in the specimens were measured on a high precision 6-dial potentiometer. In each case the resistance was measured at three or four different current levels and the value corresponding to zero current obtained by extrapolation. The ratio of the resistance of the sample at the ice-point to that at the helium-point was found to be 393 . This value is believed to be accurate to within 1 percent. However, it corresponds to an average value over a considerable length of the sample and the sample may not have been uniform in purity throughout.

A set of knife edges of known separation was fastened to the $2-\mathrm{cm}$ bar during the first set of ice-point resistance measurements. The knife edges acted as potential taps. Using the known separation of the knife edges and the cross-sectional area of the bar, the icepoint resistivity, corrected to $0{ }^{\circ} \mathrm{C}$ dimensions, was determined to be $9.847 \mu \Omega \mathrm{cm}$, accurate to within $\pm 0.010 \mu \Omega \mathrm{cm}$.

A length of $0.05 \mathrm{~cm}$ platinum wire, drawn from the same ingot as the thermal conductivity sample, was electrically annealed in air for $1 \mathrm{hr}$ at about $1450^{\circ} \mathrm{C}$. The electromotive force of this wire versus the platinum standard Pt 27 [16] was measured by the NBS Temperature Section with the reference junctions at $0{ }^{\circ} \mathrm{C}$. The values obtained (at 100 deg intervals) increased in an essentially linear manner from $0 \mu \mathrm{V}$ at $0{ }^{\circ} \mathrm{C}$ to $+15 \mu \mathrm{V}$ at $1100{ }^{\circ} \mathrm{C}$. This indicates that the sample used in the present investigation was less pure than $\mathrm{Pt} 27$.

The temperature coefficient of resistance, $\alpha=\left(R_{100}-R_{0}\right) / 100 R_{0}$, between the ice-point and the steam-point is often used as an indication of the purity of resistance thermometer grade platinum. The limiting value of $\alpha$ for extremely pure platinum is given by Berry [17] to be 0.003928 . The size and low resistance of the thermal conductivity specimen precluded a highly accurate direct determination of $\alpha$ on the specimen using existing equipment. On the basis of the electrical resistivity measurements (described later) on the necked-down portion of the specimen, $\alpha$ had a value in the range $0.003876 \leqslant \alpha \leqslant 0.003916$. The relatively large uncertainty in $\alpha$ arises from the use of platinum versus platinum- 10 percent rhodium thermocouples to measure the temperature near $100{ }^{\circ} \mathrm{C}$. Berry [17] gives a plot which correlates $\alpha$ with the ratio of the resistance of a sample at absolute zero to that at the ice-point. He also correlates the resistance at absolute zero with that at the helium-point. On the basis of Berry's correlations, the ice-point to heliumpoint resistance ratio for the thermal conductivity specimen used in the present investigation corresponds to $0.003907 \leqslant \alpha \leqslant 0.003916$. This is not inconsistent with the range of values obtained from the electrical resistivity measurements.

Although $\alpha$ could have been measured directly with high accuracy on the $0.05 \mathrm{~cm}$ platinum wire, this was not done since the results would not necessarily be valid for the $2 \mathrm{~cm}$ bar, owing to possible differences in purity and annealing. Corruccini [18] gives an empirical expression, due to Wm. F. Roeser, correlating $\alpha$ with the electromotive force versus $\mathrm{Pt} 27$ with the junction at $1200{ }^{\circ} \mathrm{C}$ and the reference junctions at $0{ }^{\circ} \mathrm{C}$. Extrapolation of the emf measurements mentioned above, indicates an emf of $+16 \mu \mathrm{V}$ at 1200 ${ }^{\circ} \mathrm{C}$, corresponding on the basis of Roeser's expression, to $\alpha \approx 0.003914$ for the $0.05 \mathrm{~cm}$ wire drawn from the same material as was used to fabricate the thermal conductivity specimen.

A cooperative project, involving NBS and several producers of thermometric grade platinum, is currently underway to study the properties of pure platinum. If as a result of this project, it appears that further characterization is indicated for the platinum used in the present investigation, such characterization will be performed on material which is being reserved for that purpose. 


\section{Method and Apparatus}

\subsection{Method}

As discussed in the introduction, it was decided to build a single apparatus in which thermal conductivity could be measured by both an absolute guarded longitudinal heat flow method (nonelectrical method) and by a method in which a necked-down portion of the sample was heated directly by passage of an electric current (electrical method). The specimen configuration selected for these measurements is shown in figure 1. The specimen (A) was raised to the desired temperature level by means of the heaters $Q_{1}$ and $Q_{3}$. In the longitudinal heat flow method, the heater, $Q_{2}$, located slightly above the center of the bar produced a temperature gradient along the portion of the bar below $Q_{2}$. Heat from this heater was prevented from flowing up the bar by adjusting $Q_{3}$ so that there was negligible temperature difference across the necked-down region of the specimen. Lateral heat losses from the bar were minimized by matching the temperature distribution along the guard to that along the specimen. Thermal conductivity was calculated from the measured temperature distribution along the lower portion of the bar, the power input to the central heater, and the geometry.

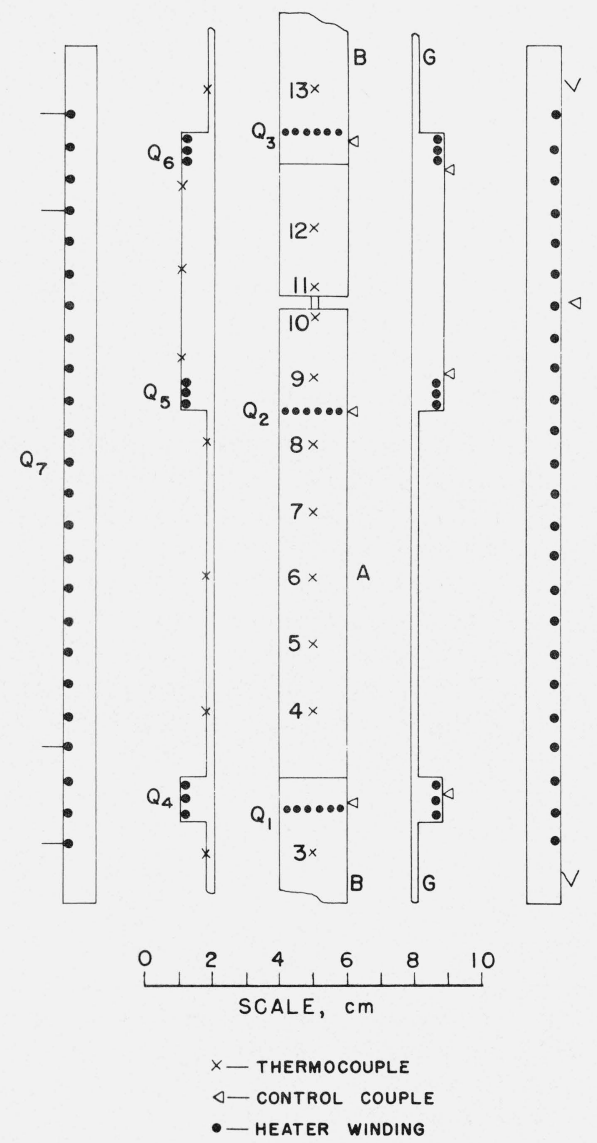

Figure 1. Schematic diagram showing locations of heaters and thermocouples in the apparatus.
In the electrical method, where the sample was directly heated by passage of an electric current, the voltage drop across the necked-down region of the specimen was measured as a function of current, while the maximum temperature rise in the neck was computed from the change in electrical resistance (due to a given change in current) and the temperature coefficient of resistance of the material. The thermal conductivity was determined from the voltage drop across the neck, the computed maximum temperature rise in it, and the electrical resistivity of the material.

The apparatus is described in detail in this section. The experimental test procedures and calculation procedures for the nonelectrical method are described in sections 4.1 and 4.2 ; those for the electrical method are described in sections 5.1 and 5.2.

\subsection{Mechanical Configuration}

The mechanical configuration of the apparatus is illustrated diagrammatically in figure 2 and described in detail below.

\section{a. Specimen}

The specimen (A) was a bar $2 \mathrm{~cm}$ in diameter by $18.4 \mathrm{~cm}$ long with a $0.11 \mathrm{~cm}$ diam by $0.33 \mathrm{~cm}$ long neck machined in it $4.1 \mathrm{~cm}$ from the upper end. A special technique, described by O'Hagan [9], had to be developed for machining the neck due to its structural

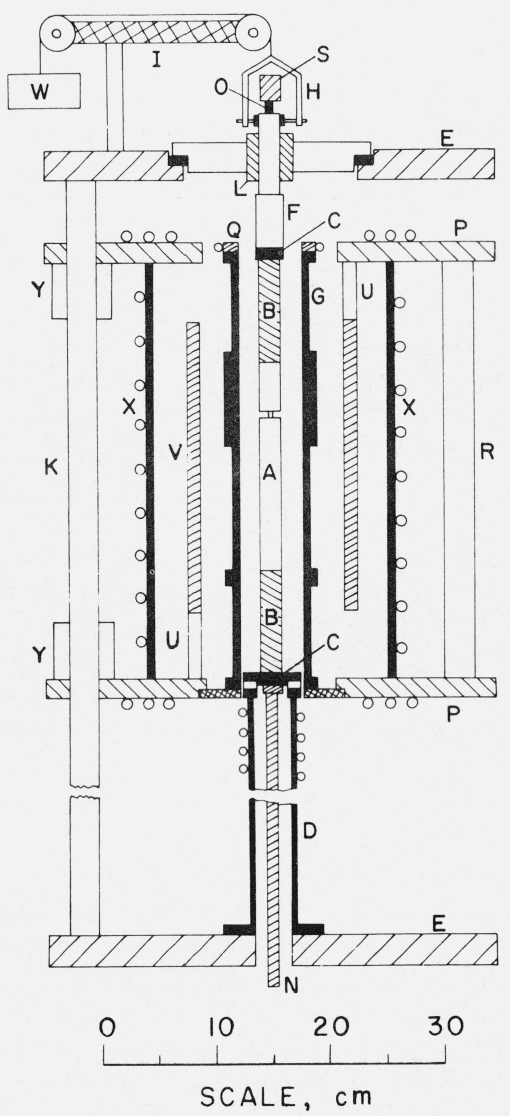

FIGURE 2. The apparatus (components are identified in the text). 
weakness. Hollow molybdenum extensions (B) of the same diameter as the specimen were screwed to the specimen (A) at both ends. The open ends were brazed to copper blocks $(C)$ that served as heat sinks. The molybdenum extensions were filled with high purity "coral" alumina. The lower end of the specimen assembly $(\mathrm{B}-\mathrm{A}-\mathrm{B})$ was bolted to, but electrically insulated from, a brass flange which was welded to a water-cooled brass column (D). This column was firmly bolted to plate (E) which served as a base for the apparatus.

One of the major problems with the necked-down specimen was that of protecting the neck from mechanical strain due to tension, compression, torsion, or bending. Any clamp supporting the neck would have had to be electrically insulated from the specimen and differential thermal expansion between the clamp and specimen could have introduced strain in the neck. As an alternative to a clamp it was decided to counterbalance the load on the neck due to the weight above it so that there would be only a small net force on the neck. The weight of platinum above the center of the neck was computed from dimensional measurements and from the measured density of the specimen, and the components extending from the upper end of the specimen were weighed before assembly.

The counterweight (W) was suspended from a string which passed over two pulleys and attached to an aluminum hanger $(\mathrm{H})$. The pulley wheels were mounted on low-friction bearings having a starting force of less than $1 \mathrm{~g}$ each. A molybdenum well $(\mathrm{F})$, which was brazed to the upper copper block $(\mathrm{C})$, passed through a linear bearing $(\mathrm{L})$ which served to maintain the upper part of the specimen in precise alinement with the lower part, and presented negligible resistance to the free vertical motion of the specimen resulting from thermal expansion. This bearing was mounted on the upper plate (E) but electrically insulated from it. The two aluminum plates $(\mathrm{E}, \mathrm{E})$ were connected by three tie bars $(\mathrm{K})$ to form a rigid framework for maintaining proper specimen alinement. An auxiliary device, described by O'Hagan [9], prevented the upper part of the specimen from rotating but still allowed free vertical motion. Current was introduced to the specimen via a copper $\operatorname{rod}(\mathrm{N})$ at the lower end and through a hollow molybdenum electrode $(\mathrm{O})$ at the upper end. The upper electrode was brazed to a copper support (S) which was fastened to, but electrically insulated from, the upper plate $(\mathrm{E})$. The molybdenum well $(\mathrm{F})$ contained a liquid metal alloy into which the electrode dipped thereby affording a flexible current connection. The buoyant force of the liquid metal on the electrode contributed to the load on the neck and was compensated for in the counterweight. The electrode was fixed but the molybdenum well moved upwards with the specimen due to thermal expansion during test runs. This changed the buoyant force and consequently put a load on the neck. The maximum change in buoyant force was only $3 \mathrm{~g}$, however, which would not strain the neck significantly. The liquid metal used was a gallium-indium eutectic alloy chosen primarily for its low vapor pressure and its comparatively low freezing temperature of
$15.7{ }^{\circ} \mathrm{C}$. The requirement for low vapor pressure was dictated by a need to evacuate the system. Preliminary tests were run to evaluate the uncertainty in buoyant force due to surface tension and sticking of the galliumindium to the molybdenum surfaces. A very definite hysteresis effect was observed as the electrode was moved relative to the well and then returned to its initial position. The largest uncertainty in buoyant force was determined to be about $4 \mathrm{~g}$. The choice of molybdenum as the electrode and well material stemmed from its compatability with gallium, which reacts with most other metals, and from the fact that molybdenum is wetted by gallium. The current feed-in system also served as a heat sink for the upper part of the specimen assembly. The hollow molybdenum electrode was internally cooled by circulating water at a temperature higher than the freezing point of the gallium-indium eutectic alloy.

\section{b. Furnace and Guard}

The inner core $(\mathrm{G})$, or the guard as it is called, was a molybdenum tube of $5.7 \mathrm{~cm}$ inside diameter. Since the inner core acted as a thermal guard to prevent heat losses from the specimen, it was considered more desirable to make it from metal rather than from ceramic so that the temperature distribution along it could be more easily controlled and more accurately measured. The bottom of the guard was attached to a water-cooled brass plate $(\mathrm{P})$. A water-cooled brass ring (Q) was attached to the upper end of the guard. The outer furnace core $(\mathbf{V})$ was an aluminum oxide tube supported top and bottom by three $1-\mathrm{cm}$ diam aluminum oxide rods (U).

The exterior portion of the furnace consisted of a water-cooled shell $(\mathrm{X})$ supported between two watercooled plates $(\mathrm{P})$. Attached to the upper plate of the furnace was a split nut. This nut engaged a lead screw mounted between the plates $(\mathrm{E}, \mathrm{E})$ and by turning the screw the furnace could be moved up or down. Ready access to the specimen was thereby afforded. The three rods $(\mathrm{K})$ acted as guide rods for the furnace. Six linear bearings $(Y)$ attached to the furnace plates ensured alinement and permitted the furnace to move up and down freely. The correct vertical location of the guard relative to the specimen was determined when a probe attached to the upper end of the guard made electrical contact with a plate attached to the molybdenum well at the upper end of the specimen assembly. When the furnace had been positioned, the indicating probe attached to the guard was removed.

The space between the specimen and the molybdenum guard and that between the guard and the water-cooled shell were filled with fine high-purity aluminum oxide powder of low thermal conductivity and low bulk density $\left(0.16 \mathrm{~g} / \mathrm{cm}^{3}\right)$.

\section{c. Environmental System}

The entire apparatus was mounted inside a 24-in diam metal bell jar to enable operation in an inert atmosphere. A 4-in oil diffusion pump and a $5 \mathrm{cfm}$ mechanical pump were used to evacuate the system prior to refilling with argon or helium. Initial evacua- 


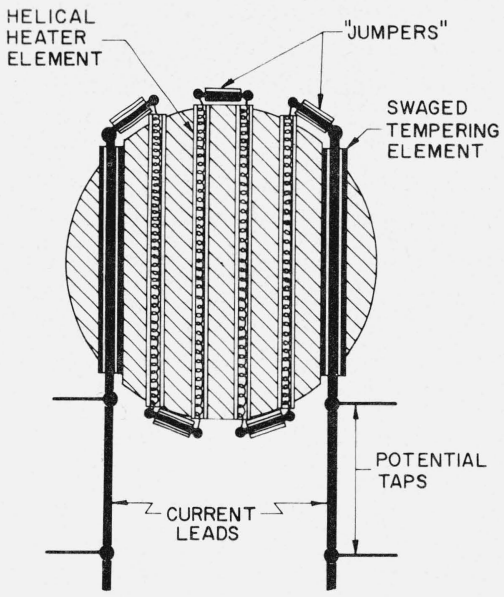

FigurE 3. Schematic diagram showing the construction of the specimen heater.

tion was controlled to avoid disturbance of the fine powder insulation.

\subsection{Thermal Configuration}

The heater and thermocouple locations on the specimen and guard are shown in figure 1.

\section{a. Specimen}

The heaters, $Q_{1}$ and $Q_{3}$, used to raise the mean temperature of the sample were located in the molybdenum extensions. These heaters consisted of six series-connected helical coils of $0.02 \mathrm{~cm}$ diam platinum-thirty percent rhodium wire insulated from the surrounding metal by thin-wall aluminum oxide tubing. Platinel ${ }^{2}$ thermocouples were attached adjacent to heaters $Q_{1}$ and $Q_{3}$ for use in controlling the temperatures at these locations.

The central heater, $\mathrm{Q}_{2}$, was contained in six holes drilled through the platinum bar and was constructed as shown in figure 3 . The inner four holes were $0.1 \mathrm{~cm}$ in diameter and accommodated helical elements contained in thin-wall aluminum oxide tubing. The elements were made from $0.013 \mathrm{~cm}$ diam platinum-10 percent rhodium wire, the outside diameter of the helix being $0.05 \mathrm{~cm}$ and the pitch $0.025 \mathrm{~cm}$. The outer two holes were $0.16 \mathrm{~cm}$ in diameter and accommodated "swaged elements" having platinum-10 percent rhodium sheaths insulated from platinum -10 percent rhodium heater wires by compacted $\mathrm{MgO}$ powder insulation. The swaged elements were a snug fit in the holes so that there was good thermal contact between the sheath and the bar, and consequently good thermal coupling between the heater and the bar. The six elements were connected in series as in heaters $Q_{1}$ and $\mathrm{Q}_{3}$. Platinum heater leads, $0.05 \mathrm{~cm}$ in diameter, were welded to the ends of the swaged elements. The good thermal contact in the swaged elements ensured that the temperature at the ends of the heater

${ }^{2}$ Platinel has a high thermal emf, approximately that of Chromel $\mathrm{P}$ versus Alumel The negative leg of the thermocouple is 65 percent $\mathrm{Au}, 35$ of Chromel $\mathrm{P}$ versus Alume and the positive leg is 55 percent $\mathrm{Pd}, 31$ percent $\mathrm{Pt}$, and 14 percent $\mathrm{Au}$ (Platinel 7674). closely approximated that of the specimen. Moreover, the current leads extended radially from the heater in an isothermal plane. The combined result was to minimize heat losses via the leads. Two $0.02 \mathrm{~cm}$ platinum10 percent rhodium potential leads were welded to each of the current leads, one at the junction of the heater and the current lead, and the other about $1 \mathrm{~cm}$ back along the current lead. The two platinum -10 percent rhodium potential leads together with the intervening section of platinum current lead served as a differential thermocouple to determine the temperature gradient in the current lead. By taking potential readings with the current flowing in the forward and reverse directions, the IR drop in the current leads could be accounted for and the temperature gradients therein determined. These data were used in computing heat flows along the leads. The potential drop across the inner taps was used in computing the power generated in the heater. The distances from the heaters to the nearest thermocouples and potential taps were such that perturbations in heat flow and electric current flow generated by the presence of the heaters decayed to an insignificant level at the position of the thermocouples or potential taps (see appendix B of O'Hagan [9]).

Five thermocouples, spaced $2 \mathrm{~cm}$ apart, were located in the gradient zone of the specimen, with the lowermost one (designated 4 in fig. 1) being $2 \mathrm{~cm}$ from the end of the specimen. The thermocouples were fabricated from $0.020 \mathrm{~cm}$ diam platinum and platinum 10 percent rhodium wires which were annealed in air at about $1450{ }^{\circ} \mathrm{C}$ for $1 / 2 \mathrm{hr}$ and then butt-welded together. They were pressed into $0.018 \mathrm{~cm}$ wide by $0.023 \mathrm{~cm}$ deep horizontal slits in the surface of the specimen thereby replacing the metal removed in machining the slits. By virtue of the fact that the specimen was fairly pure platinum with essentially the same absolute thermoelectric power as the platinum leg of the thermocouple the junction of each thermocouple was effectively at the point where the platinum-10 percent rhodium leg first made contact with the specimen, and the temperature measured was the temperature at that point. The platinum-10 percent rhodium wire emerging from its groove extended a short way around the specimen in the same isothermal planeinsulated from the specimen in broken ceramic tubing-so as to minimize the amount of heat conducted away from the junction. Similar thermocouples were located in the molybdenum extensions, three in each, to measure the temperature distribution along them. This information was essential to the mathematical analysis of the system.

Additional thermocouples were located on either side of the neck (locations 9, 10, 11, and 12 in fig. 1). These were fabricated from annealed $0.038 \mathrm{~cm}$ diam platinum and platinum- 10 percent rhodium wire and pressed into slits. In addition to measuring temperature, these thermocouples were wired at the selector switches so that the platinum legs could be used to measure voltage drops across the neck when an electric current was flowing through the neck. With no current flowing, the platinum-10 percent rhodium legs, in 
conjunction with the platinum neck, could be used as a differential thermocouple to control the differential temperature across the neck in the longitudinal heat flow method of measurement.

\section{b. Guard}

The guard had three heaters, $\mathrm{Q}_{4}, \mathrm{Q}_{5}$, and $\hat{\mathrm{Q}}_{6}$, at positions corresponding to those on the specimen assembly. All three were swaged heaters with platinum-10 percent rhodium sheaths and heating elements, and $\mathrm{MgO}$ insulation. They were pressed into grooves machined in the guard, thus giving good thermal contact. The end heaters $\left(Q_{4}\right.$ and $\left.Q_{6}\right)$ were used to keep the guard at the desired temperature. The central heater $\left(Q_{5}\right)$ was used to produce a temperature gradient in the guard matching that in the specimen.

The guard was electrically grounded but the heaters were isolated. Platinel control thermocouples were peened into the guard adjacent to each of the heaters.

Twelve thermocouples were located on the guard, three in the gradient zone, three in the isothermal zone, and three in each of the end zones. All the thermocouples were $0.038 \mathrm{~cm}$ platinum versus platinum -10 percent rhodium with the junctions pressed into slits machined in the guard. The thermocouple wires were taken one turn around the guard in broken ceramic tubing in an isothermal plane and cemented to the guard with high purity alumina cement. This helped to temper the thermocouple leads and reduce the amount of heat conducted away from the junction by the leads. Within the furnace all the thermocouples were insulated in single-bore ceramic tubes. For the remainder of their lengths the wires were insulated in flexible fiber-glass sleeving. All the thermocouples, both from the guard and the specimen assembly, went to a junction box mounted on the inside of the feedthrough ring. There they were torch welded to identical wires which were taken through wax vacuum seals to an ice bath. All the Platinel control couples went to terminal strips on the upper plate of the furnace. There they were spotwelded to Chromel $\mathrm{P}$ and Alumel wires coming from the temperature controllers.

The aluminum oxide outer core $(\mathrm{V})$ was provided with a heater winding $(0.1 \mathrm{~cm}$ diam molybdenum) to bring the furnace as a whole to temperature and to reduce heat losses from the molybdenum guard and the power load on its heaters. A Platinel control thermocouple was mounted on the outer core $(\mathrm{V})$.

\subsection{Instrumentation}

\section{a. Temperature Control}

In the longitudinal heat flow method of measuring thermal conductivity, the platinum- 10 percent rhodium legs of the outer pair of thermocouples in the neck region were used in conjunction with the neckeddown portion of the specimen as a differential thermocouple to control the power to heater $\mathrm{Q}_{3}$, and thus maintain essentially a zero temperature differential across the neck. The signal from this thermocouple was amplified by a chopper-stabilized d-c amplifier and fed into a current-adjusting-type proportional controller incorporating automatic reset control and rate control. The output of the proportional controller regulated the power to the heater by means of a transistorized current amplifier fed by a regulated d-c power supply. In the electrical method of measuring thermal conductivity, an electric current flowed through the specimen and the above system of control could not be employed. In this case the Platinel control couple adjacent to heater $Q_{3}$ was put in series opposition with a signal from an adjustable constant voltage source and the resultant signal fed to the proportional controller which regulated the power to $\mathrm{Q}_{3}$. The external signal was manually adjusted to give zero temperature differential across the neck.

The specimen heater $\left(\mathrm{Q}_{2}\right)$ was fed constant voltage $( \pm 0.01 \%)$ from a regulated $\mathrm{d}$-c power supply. Power to heater $Q_{1}$ and to the three guard heaters $\left(Q_{4}\right.$, $\mathrm{Q}_{5}$, and $\mathrm{Q}_{6}$ ) was supplied by variable-voltage transformers, which in turn were fed by voltage-regulated isolation transformers. Power to each heater was regulated by individual thermocouple-actuated controllers. Power to the heater winding $\left(Q_{7}\right)$ on the alumina core was supplied by a variable-voltage transformer fed by a voltage-regulated isolation transformer. The current was manually ratioed among the three heater sections. The total power to this heater was regulated by a single thermocouple-actuated controller. All heaters were supplied by separate isolation transformers or power supplies to minimize current leakage effects.

\section{b. Temperature Measurement}

The noble metal leads of the thermocouples were brought to an ice bath, where they were individually joined to copper leads. The copper leads went in shielded cables to a bank of double-pole selector switches of the type used in precision potentiometers. The selector switches were housed in a thermally insulated aluminum box with $1 \mathrm{~cm}$ thick walls. The copper leads were thermally grounded to (but electrically insulated from) the switch box to minimize heat transfer directly to the switches. The emfs of the specimen thermocouples were read on a calibrated six-dial high-precision potentiometer to $0.01 \mu \mathrm{V}$, using a photocell galvanometer amplifier and a secondary galvanometer as a null detector. (Due to thermal emfs in the potentiometer and circuitry, these emfs were probably not meaningful to better than $\pm 0.05 \mu \mathrm{V}$.) The emfs of all other thermocouples were read on a second precision potentiometer to $0.1 \mu \mathrm{V}$ using an electronic null detector.

\section{c. Power Measurement}

Power input to the specimen heater was measured using a potentiometer in conjunction with a highresistance volt box to measure the drop across the inner set of potential taps, and a standard resistor in series with the heater to measure the current. 


\section{d. Resistance Measurement}

All electrical resistance measurements were made by measuring the current (from a 0-100 A regulated d-c power supply) flowing through the specimen, utilizing a calibrated $0.001 \Omega$ standard resistor, and by measuring the appropriate voltage drop in the snecimen, using a potentiometer.

\section{Longitudinal Heat Flow Method}

\subsection{Experimental Procedure}

\section{a. Preliminaries}

The furnace was heated to $150{ }^{\circ} \mathrm{C}$ and the system evacuated to $3 \times 10^{-4}$ torr. Initial pump-down was through a needle valve to give a sufficiently low rate so as not to disturb the very light powder insulation. When the pressure had fallen below $10^{-1}$ torr, the diffusion pump was turned on, pumping initially through the needle valve, and, when the pressure was below $10^{-2}$ torr, through the 4 -in port. After pumping for $24 \mathrm{hr}$, the pumps were turned off and the system backfilled with high purity (99.99\%) argon. The argon was bled in slowly through a needle valve to avoid disturbing the powder. The pressure was allowed to build up to almost 1 atm before the valves were shut off and the cycle of evacuating and backfilling repeated. The final argon pressure after the second backfilling was about three-quarters of an atmosphere.

The cooling-water flows to the system were adjusted to the desired levels as indicated on flow-meters. The water was pressure-regulated to maintain constant flow rate. A control thermocouple on the specimen was wired to shut all the heaters off if its temperature exceeded a predetermined level. This was a safety precaution in the event of an interruption in the coolingwater flow.

The test procedures are described in detail below. To facilitate the discussion let us refer to figure 1 . The region of the specimen below the specimen heater, $\mathrm{Q}_{2}$, will be referred to as the lower part of the specimen, and the region above $Q_{2}$ as the upper part of the specimen.

\section{b. Description of Tests}

In the longitudinal heat flow method of measuring the thermal conductivity each datum point was computed by simultaneous solution of three tests:

1. an "isothermal" test with no power input to the specimen heater $\left(Q_{2}\right)$ and with the temperature distribution on the guard adjusted to closely match that on the specimen.

2. a "matched" gradient test with sufficient power input to the specimen heater to maintain the desired longitudinal temperature gradient in the specimen and with a matched temperature distribution on the guard.

3. an "unmatched" gradient test with the power input to the specimen heater and the temperature at the center of the measuring span the same as in the "matched" gradient test, and with the temperature distribution on the guard parallel to that on the specimen but 10 deg cooler.

\section{Matched Gradient Test}

The furnace temperature was raised by means of heater $Q_{7}$. The power to the specimen heater, $Q_{2}$, was adjusted to give a temperature gradient of 5 $\mathrm{deg} / \mathrm{cm}$ in the lower part of the specimen. Power to $\mathrm{Q}_{3}$ was automatically controlled, using a proportional controller, to maintain a minimum temperature drop across the neck. The Pt-10 percent Rh legs of thermocouples 9 and 12 were used in conjunction with the necked-down portion of the specimen as a differential thermocouple activating the proportional controller. The temperature drop across the neck never exceeded $0.1 \mathrm{deg}$. The specimen was maintained at the required mean temperature by thermostatting the power to the lower heater $Q_{1}$.

The temperature distribution along the guard was forced to match that along the specimen by adjusting the controllers for heaters $Q_{4}, Q_{5}$, and $Q_{6}$. Temperatures at corresponding locations on the specimen and the guard generally agreed to within $1 \mathrm{deg}$.

After allowing time for the system to come to equilibrium, readings were taken of the thermocouple emfs and the voltage and current to the specimen heater, $Q_{2}$. Normally these data were taken three times over a period of about $2 \mathrm{hr}$. The temperatures never drifted more than a few hundredths of a degree from one set of readings to the next and the three sets of data were averaged. When the drift between the first and second sets of readings was less than $0.01 \mathrm{deg}$, the third set of readings was not taken. On completion of the last set of readings, the voltage drops between the inner and outer taps of each current lead were measured with the heater current flowing normally and then reversed.

\section{Unmatched Gradient Test}

Upon completion of the "matched" gradient test the controllers for the guard heaters $Q_{4}, Q_{5}$, and $\mathrm{Q}_{6}$ were adjusted to lower the temperatures on the guard by $10 \mathrm{deg}$ while maintaining the temperature distribution parallel to that on the specimen. With the guard at the lower temperature heat losses from the specimen to the surrounding insulation were significantly increased and the heat flow in the specimen reduced. As a result, the temperature gradient in the specimen and its mean temperature were decreased. The power to heater $Q_{1}$ was adjusted to restore the specimen to the initial mean temperature. The system was then allowed to equilibrate and the same data were taken as for the "matched" gradient test.

\section{Isothermal Test}

For the "isothermal" test heater $Q_{2}$ was shut off and heater $Q_{1}$ adjusted until the specimen was approximately isothermal. No adjustments had to be made to $\mathrm{Q}_{3}$ as the controller automatically adjusted to maintain $T_{11}-T_{10}=0$. The guard heaters were likewise adjusted until the temperature distribution on the guard once again matched that on the specimen. When the system was in equilibrium, the data mentioned above were taken, with the exception of the power to the specimen heater which was shut off. 
At $1100{ }^{\circ} \mathrm{C}$ an additional "matched" gradient test was run after the three regular tests were completed. The extra data obtained in this test served as a check on drifts in thermocouple calibrations during the testing period.

$$
\text { c. Testing Sequence }
$$

All of the measurements described above were made at a number of temperatures. Tests were first run in air at $100{ }^{\circ} \mathrm{C}$, then in argon at $100,300,500$, $700,600,400$, and $200{ }^{\circ} \mathrm{C}$ in that order. One of the guard heaters would short out at about $750{ }^{\circ} \mathrm{C}$ and consequently the upper limit on the first run was $700{ }^{\circ} \mathrm{C}$. After completing that run in argon the system was evacuated and backfilled with helium $(99.99 \%$ pure) to a pressure of about three-quarters of an atmosphere. The helium, having a much higher thermal conductivity than argon, changed the effective thermal conductivity of the insulation surrounding the specimen. Tests were run in helium at 200 and $400{ }^{\circ} \mathrm{C}$ to experimentally evaluate heat losses from the specimen to the insulation. The system was then opened up and the trouble with the guard heater corrected. The furnace was filled with fresh powder insulation, the powder being packed lightly around the neck to ensure that the necked-down region was uniformly filled with insulation. The system was refilled with argon as described at the beginning of this section and tests were run at $300,700,900$, and $1100{ }^{\circ} \mathrm{C}$. Heater $Q_{3}$ burned out while tests were being conducted at $1100{ }^{\circ} \mathrm{C}$ by the electrical method and those tests were incomplete. The thermocouples started drifting at $1100{ }^{\circ} \mathrm{C}$ and losing their calibration due to contamination. Consequently, it was decided to terminate the tests at that point.

\subsection{Calculation Procedures and Uncertainties}

For one-dimensional steady-state heat flow, the total heat flow, $Q$, through the specimen is given by

$$
Q=-\lambda A \frac{d T}{d z},
$$

where $\lambda$ is the thermal conductivity, $A$ is the crosssectional area of the specimen, $T$ is the temperature and $z$ is the longitudinal coordinate. For moderate temperature ranges, the thermal conductivity of the specimen can be assumed to vary linearly with temperature; then (1) becomes

$$
Q=-\lambda_{0} A\left\{1+\beta_{0}\left(T-T_{0}\right)\right\} \frac{d T}{d z},
$$

where $\lambda_{0}$ is the thermal conductivity of the specimen at a reference temperature, $T_{0}$, and $\beta_{0}$ is its corresponding temperature coefficient. The difference between the heat flows in two tests is given by

$$
\begin{aligned}
Q-Q^{\prime} & =-\lambda_{0} A\left[\left(\frac{d T}{d z}\right)-\left(\frac{d T}{d z}\right)^{\prime}\right] \\
& -\lambda_{0} A \beta_{0}\left[\left(T-T_{0}\right)\left(\frac{d T}{d z}\right)-\left(T^{\prime}-T_{0}\right)\left(\frac{d T}{d z}\right)^{\prime}\right],
\end{aligned}
$$

where quantities of one test are distinquished from those of the other by use of primes. If we define the reference temperature as

$$
T_{0}=\frac{T(d T / d z)-T^{\prime}(d T / d z)^{\prime}}{(d T / d z)-(d T / d z)^{\prime}}
$$

the second term on the right-hand side of (3) vanishes, and the thermal conductivity at the reference temperature, $T_{0}$, is given by

$$
\lambda_{0}=\frac{-\left(Q-Q^{\prime}\right)}{A\left[(d T / d z)-(d T / d z)^{\prime}\right]} .
$$

The purpose of computing the thermal conductivity from data corresponding to two different powers was to correct for errors that did not depend on the power transmitted through the specimen. The most obvious errors of this type are thermocouple errors. In a simultaneous solution each thermocouple in effect measures a temperature difference so that errors in calibration of the thermocouples cancel out to first order. Further possible sources of error will become evident below. Determination of $\lambda_{0}$ involved measurement of the cross-sectional area of the specimen, the total heat flow in the specimen and the longitudinal temperature gradient in the specimen for each of the two tests. These quantities were evaluated at the position of the middle thermocouple in the measuring span.

\section{a. Cross-Sectional Area}

The effective cross-sectional area of the specimen, after correction of the measured diameter for surface roughness, was determined to be $3.1331 \mathrm{~cm}^{2}$ at $21{ }^{\circ} \mathrm{C}$. The uncertainty ${ }^{3}$ in this area was estimated to be less than 0.02 percent. The diameter at temperature $t$ $\left({ }^{\circ} \mathrm{C}\right)$ was computed from that at $25^{\circ} \mathrm{C}$ using the equation

$D_{t}=D_{25}\left(0.99978+8.876 \times 10^{-6} t+1.311 \times 10^{-9} t^{2}\right)$.

This equation was derived from smoothed thermal expansion data for platinum [19]. The cross-sectional area was then computed from the diameter.

\section{b. Heat Flow}

The total heat flow through the specimen at the position of the center thermocouple was calculated using the expression

$$
Q=P-q_{a}-q_{b}-q_{n}-q_{i}-q_{c},
$$

where $P$ is the measured electrical power input to the specimen heater;

$q_{a}$ and $q_{b}$ are the heat losses along the two leads carrying current to the specimen heater;

$q_{n}$ is the heat loss across the necked-down portion of the specimen;

${ }^{3}$ Uncertainties stated in this paper represent either (a) statistical uncertainties based on results of calibrations or (b) limits to errors conservatively estimated by the authors. 


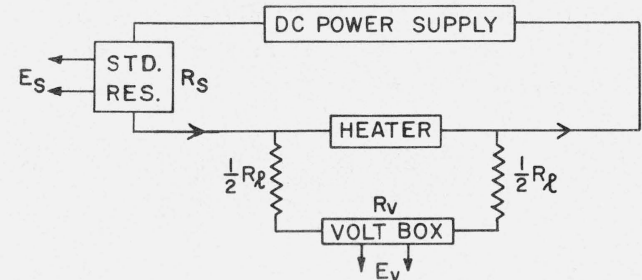

Figure 4. Circuit diagram for the specimen heater.

$q_{i}$ is the heat loss into the insulation surrounding the specimen; and

$q_{c}$ is the heat loss down the thermocouple wires and ceramic tubes next to the specimen.

Each of the quantities in (7) is considered separately below.

Power Input to Specimen Heater $(P)$ : The electrical circuit for the specimen heater is illustrated diagrammatically in figure 4 . The power input to the heater was computed using

$$
P=n E_{v}\left(1+R_{l} / R_{v}\right)\left(E_{s} / R_{s}-n E_{v} / R_{v}\right),
$$

where $E_{v}$ is the voltage drop across the output of the volt box as measured with a potentiometer, $n$ is the resistance ratio of the volt box, $E_{s}$ is the voltage drop across the standard resistor, $R_{s}$, as measured with a potentiometer, $R_{l}$ is the total resistance of the potential leads and $R_{v}$ is the total resistance of the volt box.

The potentiometer, voltbox, and shunt box were each calibrated to 0.01 percent or better. The emf of the standard cell was known to 0.01 percent or better. The correction terms in (8) for the voltage drop in the potential leads and for the current through the voltbox were small (a few tenths of a percent) and uncertainties in these corrections could not have introduced more than 0.01 percent additional error in $\mathrm{P}$. Thus the percentage uncertainty in the measured electrical power input was less than 0.05 percent.

Heat Flow in Current Leads $\left(q_{a}, q_{b}\right)$ : The circuit diagram in figure 4 shows only one set of potential leads coming from the heater. In fact there were two sets as shown in figure 5 , but only the inner set, i.e., the potential taps closer to the heater, was used in measuring the power input to the heater. The two sets of potential leads were required in measuring heat conduction along the current leads. The current leads were platinum and the potential leads platinum-10 percent rhodium. Consequently, each current lead could be used along with its two potential leads as a differential thermocouple to measure the temperature drop, $\Delta T$, between the potential taps. With current flowing to the heater the voltage drop measured between 1-2 or 3-4 was the algebraic sum of the $I R$ drop between adjacent potential taps (where $I$ is the current

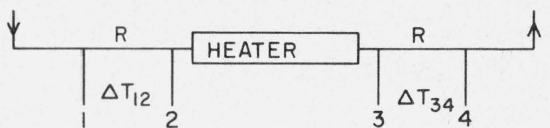

Figure 5. Arrangement of potential leads for the specimen heater. and $R$ is the resistance of the current lead between the potential taps) and the Seebeck emf due to the temperature drop, $\Delta T$, between the potential taps. Assuming no heat losses from the current leads, it can be shown $[9,20-26]$ that the heat conducted along the leads is given by

$$
q_{a, b}=\frac{\lambda \rho}{R} \Delta T-\frac{I^{2} R}{2},
$$

where $\rho$ is the electrical resistivity of the current lead and $\lambda$ its thermal conductivity. By taking measurements with the current flowing forward and reversed, $R$ and $\Delta T$ were determined for each lead, and consequently $q_{a}$ and $q_{b}$.

The heat conducted along the leads, as determined using (9), was less than 0.05 percent of the heat flowing in the specimen. These corrections were sufficiently accurate that no errors larger than 0.02 percent are believed to have been introduced into the measured thermal conductivity values by uncertainties in $q_{a}$ and $q_{b}$. We will discuss below the possible magnitude of heat losses from the current leads into the surrounding powder insulation.

Heat Flow across Neck $\left(q_{n}\right)$ : Referring to figure 1, it is seen that heat could be conducted across the necked-down region of the specimen by the neck itself and by the powder insulation surrounding it. The conductance of the powder was $\kappa \pi\left(b^{2}-a^{2}\right) / 2 l$ where $\kappa$ is the thermal conductivity of the powder, $b$ the radius of the specimen, $a$ the radius of the neck, and $2 l$ the length of the neck. The conductance of the specimen between thermocouple positions 10 and 11 was $\lambda F$ where $\lambda$ is the thermal conductivity of the specimen and $F$ is a geometric factor which was determined from the corresponding equation for electrical conductance, $I=\sigma F V$, where $I$ is the current, $\sigma$ the electrical conductivity and $V$ is the voltage drop between the thermocouples. These data were available from measurements by the electrical method. The heat flow across the necked-down region was given by

$$
q_{n}=\left[\lambda F+\kappa \frac{\pi\left(b^{2}-a^{2}\right)}{2 l}\right] \Delta T,
$$

where it is assumed that the temperature differential across the insulation was the same as that measured between the thermocouples.

The correction for heat flow across the neckeddown region of the specimen was always less than 0.05 percent of $P$. Errors in the temperature drop across the neck due to possible inhomogeneities in the thermocouple leads or to stray thermal emfs would, for the most part, cancel since they were common to $q_{n}$ and $q_{n}^{\prime}$ (i.e., corresponding to $Q$ and $Q^{\prime}$ ). At 300 ${ }^{\circ} \mathrm{C}$ a series of tests were run in which the temperature drop across the neck was held in turn at about $-5,0$, and $+5 \mathrm{deg}$, a range 20 times larger than that which occurred during normal measurements. The corresponding values for $\left(q_{n}-q_{n}^{\prime}\right)$ were about +1 percent, 0 percent, and -1 percent, respectively, of 
$P$. The three thermal conductivity values obtained, using (10) to effect the correction for heat flow across the neck, fell within a range of less than \pm 0.02 percent. For normal tests, in which the temperature across the necked-down region was maintained quite small, it is felt that any uncertainty in the measured thermal conductivity values due to this source was less than 0.02 percent.

Heat Loss into the Insulation $\left(q_{i}\right)$ : In order to determine $q_{i}$, the heat exchange between the specimen and the surrounding insulation, it was necessary to perform an extensive mathematical analysis. If the temperature distribution along the guard exactly matched that along the specimen there would have been no radial heat exchange between the specimen and the guard. However, there would still have been an exchange of heat between the specimen and the surrounding insulation in order to provide the longitudinal heat flow in the insulation adjacent to the specimen.

The heat flow from an elemental length of the surface of the specimen was

$$
d q_{i}=2 \pi a \kappa\left(\frac{\partial \theta}{\partial r}\right)_{r=a} d z,
$$

where $a$ is the radius of the specimen, $\kappa$ the thermal conductivity of the insulation, $\theta$ the temperature in the insulation relative to an arbitrary fixed temperature, $r$ the radial coordinate, and $z$ the longitudinal coordinate. The net heat flowing across the surface $r=a$ between $z_{1}$ and $z_{2}$ was

$$
q_{i}\left(z_{1}, z_{2}\right)=2 \pi a \int_{z_{1}}^{z_{2}} \kappa\left(\frac{\partial \theta}{\partial r}\right)_{r=a} d z
$$

where $\kappa$ is, in general, temperature dependent. Let us define a new potential, $\xi$, that satisfies the relation

$$
\kappa_{0} \nabla \xi=\kappa(\theta) \nabla \theta,
$$

where $\kappa_{0} \equiv \kappa(0)$. Integrating (13),

$$
\xi=\frac{1}{\kappa_{0}} \int_{0}^{\theta} \kappa(\theta) d \theta
$$

where we have selected the integration constant so that $\xi=0$ when $\theta=0$. Writing (12) in terms of $\xi$ we get

$$
q_{i}\left(z_{1}, z_{2}\right)=\kappa_{0} D\left(z_{1}, z_{2}\right),
$$

where

$$
D\left(z_{1}, z_{2}\right)=2 \pi a \int_{z_{1}}^{z_{2}}\left(\frac{\partial \xi}{\partial r}\right)_{r=a} d z .
$$

The factor $D\left(z_{1}, z_{2}\right)$ was determined by analyzing the heat flow in the hollow cylinder of powder insulation between the specimen and the guard, using the measured temperature distributions along the speci- men assembly and along the guard cylinder as boundary conditions. Polynomial expressions relating temperature to longitudinal position were used to describe these temperature distributions in the regions between the heaters. In the intervening regions near the heaters, smoothing cubics [27] were used which provided continuity of temperature and longitudinal temperature gradients. The evaluation of $D\left(z_{1}, z_{2}\right)$ is described more fully in appendix A.

Since the heat flow in the specimen was to be evaluated at the position of the center thermocouple in the gradient region, all the heat loss to the insulation from the location of the heater down to the position of the center thermocouple had to be considered. In addition, heat losses in the region between the specimen heater and the neck had to be considered since these had to be provided by the specimen heater. The neck, in effect, could be considered as the upper end of the specimen for purposes of this analysis, since any heat exchanges between the powder and the specimen above the neck did not affect that part of the specimen below the neck as long as zero temperature differential was maintained across the neck. Therefore, in evaluating $q_{i}$, the limits of integration for $D\left(z_{1}, z_{2}\right)$ were the position of the center thermocouple $\left(z_{1}\right)$ and the position of the center of the neck $\left(z_{2}\right)$.

The correction $\left(q_{i}-q_{i}{ }^{\prime}\right)$ for heat exchange with the powder insulation was potentially a large source of error and considerable effort was expended to, first, keep this correction small and, second, evaluate it accurately. Evaluation of this correction, as seen from (15), required a knowledge of the integral, $D\left(z_{1}, z_{2}\right)$, and of the thermal conductivity, $\kappa_{0}$, of the insulation.

. Numerous factors could have adversely affected the determination of $D\left(z_{1}, z_{2}\right)$. The use of logarithmic functions to define the radial temperature distribution across the ends of the hollow cylinder of insulation was an approximation. However, it is easily shown that the potential distribution near the specimen was not significantly affected by the boundary conditions at the remote ends of the extensions.

In the mathematical analysis it was assumed that the temperatures on the inner surface of the guard were the same as the temperatures measured on the outer surface. The molybdenum guard had high thermal conductivity so that any radial temperature gradients in the guard would be small and the associated errors would tend to cancel on simultaneous solution of the gradient and isothermal tests. Angular variations in the temperature distribution on the guard could have arisen if the specimen and guard were not concentric or if the insulation between the specimen and the guard was not packed uniformly. Great care was taken to avoid both of these conditions. Any angular variations would have been approximately the same for two tests at the same mean temperature and so the associated errors would in large part cancel under simultaneous solution. Such would not be the case for errors arising from uncertainties in the longitudinal positions of the thermocouples since the temperature distribution along the guard cylinder in 
the gradient test differed from that in the isothermal test. The necessary steps were taken to ensure that the longitudinal position of the guard was accurately known relative to that of the specimen, and the location of the thermocouple slits both on the guard and on the specimen assembly were measured accurately prior to installation of the thermocouples.

The details of the actual temperature distributions in the heater regions where smoothing cubics [27] were used could conceivably have influenced $D\left(z_{1}, z_{2}\right)$. Except for the regions of $Q_{2}$ and $Q_{5}$, such effects should have been about the same in the gradient and in the isothermal tests, and hence would have canceled on simultaneous solution of these tests. Since the guard heaters were on the outside of a considerable thickness of high-conductivity metal, we feel that the temperature on the inside surface of the guard cylinder varied smoothly with position in the regions of the guard heaters. Thus, no significant errors were believed to be introduced by the use of a smoothing function in the region of $Q_{5}$.

R. W. Powell [28] has pointed out that a possible additional source of error, not specifically discussed by O'Hagan [9], is heat loss into the powder insulation from the external platinum jumpers which connected the elements of heater $Q_{2}$ (see sec. 3.3a and fig. 3). There were five such jumpers, each about $0.3 \mathrm{~cm}$ long, contained in aluminum oxide tubing to electrically insulate them from the specimen. Although the heat generated in the jumpers was only a small fraction of the total heat generation in the heater, these jumpers were heated, by conduction from the helical heater coils inside the specimen, to a temperature above that of the specimen. This would have resulted in a heat flow into the powder insulation surrounding the jumpers. A portion of this heat would have flowed back into the specimen but, at least in principle, a net portion of the power input to the specimen heater could have been lost from the heater jumpers with a corresponding error in the measured thermal conductivity values.

Since the temperature rise of the jumpers was dependent upon the power input to the specimen heater, the heat loss discussed in the previous paragraph was not eliminated, or even reduced, by the simultaneous solution of a matched gradient test and an isothermal test. The use of an unmatched gradient test also did not help in evaluating this source of heat loss. The smoothing functions used were quite adequate for the isothermal tests but did not truly represent the temperature distributions in the region of $\mathrm{Q}_{2}$ for the gradient tests. In view of the importance of this potential source of error, heat loss from the jumpers is considered further in appendix B, where a mathematical analysis is used to approximately evaluate this source of error. This analysis indicates that errors in the measured thermal conductivity values due to heat loss from the jumpers on heater $Q_{2}$ were less than 0.2 percent at $100{ }^{\circ} \mathrm{C}$ and less than 0.5 percent at $900{ }^{\circ} \mathrm{C}$.

A calculation (see appendix I of O'Hagan [9]), based on the degree of tempering provided by the swaged elements to which the heater current leads were attached, indicated that the current leads were only 1 to $2 \operatorname{deg} \mathrm{C}$ hotter than the adjacent specimen material. By comparison to the discussion of heat loss from the jumpers (see appendix B), which may have been over $100 \operatorname{deg} \mathrm{C}$ hotter than the specimen, we see that any errors due to heat loss from the heater leads into the powder insulation were negligible.

In analyzing the data the "isothermal" test was combined with the "matched gradient" test and with the "unmatched gradient" test to give two equations of the form (5). Inspection of eqs (5), (7), and (15) shows that the value obtained for $\lambda_{0}$ depends in a linear manner on the value assumed for $\kappa_{0}$. The effective thermal conductivity of the insulation surrounding the specimen depends on the density of the powder and the pressure and type of gas present, and is best determined under experimental conditions. This was done by simultaneous solution of two equations of the form (5) which yielded values both for the thermal conductivity of the specimen, $\lambda_{0}$, and the thermal conductivity of the insulation, $\kappa_{0}$. The thermal conductivity values obtained for the aluminum oxide insulation, in argon and in helium, were given by O'Hagan [9].

If there was a significant heat exchange between the specimen and the insulation that was not being adequately corrected for, one would expect a systematic difference between the values obtained for the thermal conductivity of the specimen in helium and those obtained in argon, due to the large difference between the thermal conductivity of the powder in the different atmospheres. In fact, however, the values measured in helium fell within the scatter band of those measured in argon indicating that any uncorrected heat exchanges were certainly less than 0.2 percent, the width of the scatter band (see sec. 4.3).

For all of the tests taken the correction $\left|q_{i}-q_{i}^{\prime}\right|$ was less than 0.1 percent of $P$. It is felt that $D\left(z_{1}, z_{2}\right)$ and $\kappa_{0}$ were each known to better than 10 percent and hence the uncertainty in $\left(q_{i}-q_{i}^{\prime}\right)$ less than 0.02 percent of $\left(P-P^{\prime}\right)$. However, in view of all the factors which conceivably could have influenced this correction, an uncertainty of 0.1 percent is assigned to the measured thermal conductivity values due to possible errors in $\left(q_{i}-q_{i}^{\prime}\right)$. To this must be added the uncertainty due to heat loss from the jumpers on heater Q.2.

Heat Loss along Thermocouple Wires and Insulators $\left(q_{c}\right)$ : The heat loss, $q_{c}$, along the thermocouples and ceramic insulators next to the specimen was computed from the expression

$$
q_{c}=\sum_{i=1}^{n} C_{i}\left(\frac{d T}{d z}\right),
$$

where $C_{i}$ is the longitudinal thermal conductance of the $i$ th wire and its insulator, $n$ is the total number of wires crossing the plane where the thermal conductivity was evaluated, and $d T / d z$ is the temperature gradient at that plane. Each $C_{i}$ was computed from the thermal conductivities and dimensions of the wire 
and insulator. This correction was rather large, falling from about 0.8 percent at $100{ }^{\circ} \mathrm{C}$ to 0.3 percent at $1100{ }^{\circ} \mathrm{C}$, the falloff being due to the rapidly decreasing thermal conductivity of the ceramic tubing. Although the thermal conductivity of the thermocouple wires was known fairly accurately $(5 \%)$ the thermal conductivity of the ceramic tubing was known only approximately (15\%). Furthermore, the cross-sectional areas of the wires and tubing were not accurately known $(5 \%)$. Thus the total conductance of the wires and the ceramic tubing was only known to about 25 percent. The corresponding uncertainty in the measured thermal conductivity values was 0.2 percent at $100{ }^{\circ} \mathrm{C}$ and 0.1 percent at $900{ }^{\circ} \mathrm{C}$.

Departure from Steady-State: The ratio of heat absorbed (or released) to that conducted in the specimen is given approximately by

$$
\frac{w c A L(d T / d t)}{\lambda A(d T / d z)}=\frac{L}{D} \frac{(d T / d t)}{(d T / d z)},
$$

where $w$ is density, $c$ is specific heat, $A$ is area, $L$ is total length of specimen below the necked-down region, $d T / d t$ is time rate of temperature change, $\lambda$ is thermal conductivity, $d T / d z$ is temperature gradient, and $D=\lambda / w c$ is thermal diffusivity. Temperatures in the system did not drift at a rate greater than 0.03 $\mathrm{deg} / \mathrm{hr}$ (i.e., $10^{-5} \mathrm{deg} / \mathrm{sec}$ ); the length, $L$, was about $14 \mathrm{~cm}$; the temperature gradient was $5 \mathrm{deg} / \mathrm{cm}$; and the thermal diffusivity of platinum in the temperature range $0-1100{ }^{\circ} \mathrm{C}$ is always greater than $0.2 \mathrm{~cm}^{2} / \mathrm{sec}$ [12]. Hence the ratio of heat absorbed (or released) to that conducted was less than \pm 0.02 percent. No correction was made for departure from steady-state conditions.

Total Uncertainty in Heat Flow: Using standard propagation of error formulas, the estimated uncertainty in $\left(Q-Q^{\prime}\right)$ was 0.4 percent at $100{ }^{\circ} \mathrm{C}$ and 0.7 percent at $1100^{\circ} \mathrm{C}$.

\section{c. Temperature Gradient}

The temperature gradient in the specimen was computed from the measured temperatures at the five thermocouple positions in the gradient region. The separations between thermocouple grooves at room temperature were accurately measured before the thermocouples were installed; the separation at elevated temperature was computed using (6). Since temperature gradients in the specimen were rather small (less than $5 \mathrm{deg} / \mathrm{cm}$ ) it was essential that the conversion of thermocouple emfs to temperature not introduce any additional uncertainties. The equation

$$
\begin{aligned}
E= & 15.83952\left(\frac{t}{1000}\right)-9.18328\left(\frac{t}{1000}\right)^{2} \\
& +7.30572\left(\frac{t}{1000}\right)^{3}-1.92753\left(\frac{t}{1000}\right)^{4} \\
& -2.50480(1.0-\exp [-4.18312(t / 1000)]),
\end{aligned}
$$

where $t$ is temperature $\left({ }^{\circ} \mathrm{C}\right)$ and $E$ is emf $(\mathrm{mV})$, was found to fit to within $l \mu \mathrm{V}$ the calibration data for the platinum versus platinum-10 percent rhodium thermocouple wire from which the specimen thermocouples were fabricated. This equation was used for converting the thermocouple voltages to temperatures.

The temperature gradient was computed by evaluating the slope, at the center thermocouple location, of the quadratic equation of least-squares fit to the five temperatures and thermocouple positions. The uncertainty in the temperature gradient due to uncertainties in effective thermocouple positions is estimated to have been less than 0.2 percent. Errors in reading thermocouple emfs did not introduce an uncertainty of more than 0.05 percent for the temperature gradients used. Errors due to heat conduction along thermocouple leads should have been negligible and were certainly less than 0.05 percent (see Appendix G of O'Hagan [9]). Due to the use of a simultaneous solution of a gradient and an isothermal test, errors in the measured temperature gradient due to variations between individual thermocouples are estimated to have been less than 0.05 percent. It is estimated that the conversion of thermocouple emfs to temperatures introduced errors of less than 0.2 percent in the temperature gradients.

The estimated overall uncertainty in the temperature gradient is estimated to have been 0.3 percent.

\section{d. Mean Temperature}

In addition to the uncertainties discussed above in the area, heat flow, and temperature gradient, there is an uncertainty in the temperatures to which the thermal conductivity values correspond. For a $0.5 \mathrm{deg}$ uncertainty in temperature, the associated uncertainty in thermal conductivity is less than 0.001 percent at $100{ }^{\circ} \mathrm{C}$ and less than 0.02 percent at $900{ }^{\circ} \mathrm{C}$.

\subsection{Results}

The experimental values obtained for the thermal conductivity of our platinum specimen by the longitudinal heat flow method are given in table 1 . The

\begin{tabular}{|c|c|c|c|c|}
\hline Test & Run & Atmosphere & $\begin{array}{c}\text { Mean } \\
\text { temperature } \\
{ }^{\circ} \mathrm{C}\end{array}$ & $\begin{array}{c}\text { Thermal } \\
\text { conductivity } \\
\text { W/cm deg }\end{array}$ \\
\hline 1 & 1 & Air & 99.6 & 0.715 \\
\hline 2 & 1 & Argon & 99.8 & .715 \\
\hline 3 & 1 & Argon & 301.0 & .728 \\
\hline 4 & l & Argon & 501.5 & .753 \\
\hline 5 & 1 & Argon & 701.2 & .784 \\
\hline 6 & 1 & Argon & 601.3 & .769 \\
\hline 7 & l & Argon & 400.2 & .740 \\
\hline 8 & 1 & Argon & 201.7 & .721 \\
\hline 9 & l & Helium & 199.6 & .721 \\
\hline 10 & i & Helium & 400.6 & .740 \\
\hline 11 & 2 & Argon & 300.0 & .729 \\
\hline 12 & 2 & Argon & 701.3 & .786 \\
\hline 13 & 2 & Argon & 900.0 & .822 \\
\hline 14 & 2 & Argon & 1100.5 & $(.866)^{u}$ \\
\hline
\end{tabular}

TABLE 1. Experimental values for the thermal conductivity of platinum as measured using the longitudinal heat flow method The values given are corrected for thermal expansion. 
TABLE 2. Typical set of data from measurements of the thermal conductivity of platinum by the longitudinal heat flow method

The data correspond to Test No. 6 in table 1.

\begin{tabular}{|c|c|c|c|}
\hline & $\begin{array}{l}\text { Matched } \\
\text { gradient }\end{array}$ & $\begin{array}{l}\text { Unmatched } \\
\text { gradient }\end{array}$ & Isothermal \\
\hline $\begin{array}{ll}\text { Temperature distribution along the } & \\
\text { specimen................................ }{ }^{\circ} \mathrm{C} \ldots . & T_{4} \\
& T_{5} \\
& T_{6} \\
& T_{7} \\
& T_{8}\end{array}$ & $\begin{array}{l}580.4 \\
590.9 \\
601.3 \\
611.7 \\
622.1\end{array}$ & $\begin{array}{l}579.0 \\
588.9 \\
598.8 \\
608.9 \\
619.0\end{array}$ & $\begin{array}{l}600.7 \\
600.6 \\
600.3 \\
600.1 \\
600.0\end{array}$ \\
\hline $\begin{array}{l}\text { Temperature gradient at the location of } \\
\text { thermocouple } T_{6} \ldots \ldots \ldots \ldots \ldots \text { deg } / \mathrm{cm} \ldots \frac{d T}{d z}\end{array}$ & 5.18 & 4.96 & -0.09 \\
\hline $\begin{array}{l}\text { Power generated in specimen } \\
\text { heater.............................. P } \\
\text { Heat flow across the necked-down }\end{array}$ & 12.818 & 12.853 & .0 \\
\hline 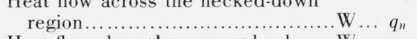 & 0.003 & -0.008 & -.002 \\
\hline Heat flow along the current leads ....W ... $q_{a}$ & $\begin{array}{l}.004 \\
.003\end{array}$ & $\begin{array}{l}.017 \\
.006\end{array}$ & $\begin{array}{l}.00 \\
.00\end{array}$ \\
\hline 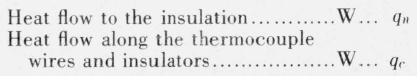 & .006 & .542 & -.001 \\
\hline
\end{tabular}

thermal conductivity values given there have been corrected for thermal expansion of the specimen. A typical set of data, including the various correction terms, is given in table 2.

A cubic equation of least-squares fit was found to fit the data (corrected for expansion) from the longitudinal heat flow method with the residuals having a standard deviation of 0.08 percent. This was significantly less than the standard deviation of the residuals from a parabola. The equation, valid over the range 100 to $900{ }^{\circ} \mathrm{C}$, is

$$
\begin{aligned}
\lambda=0.713+0.683 \times 10^{-5} t+ & 0.173 \times 10^{-6} t^{2} \\
& -0.513 \times 10^{-10} t^{3},
\end{aligned}
$$

where $t$ is temperature in ${ }^{\circ} \mathrm{C}$ and $\lambda$ is in $\mathrm{W} / \mathrm{cm}$ deg. Departures of the data points from (20) are plotted in figure 6 . With the exception of the point at $1100{ }^{\circ} \mathrm{C}$ all the data points, including the two obtained in helium, fall within \pm 0.1 percent of the curve. There were no significant differences between the values

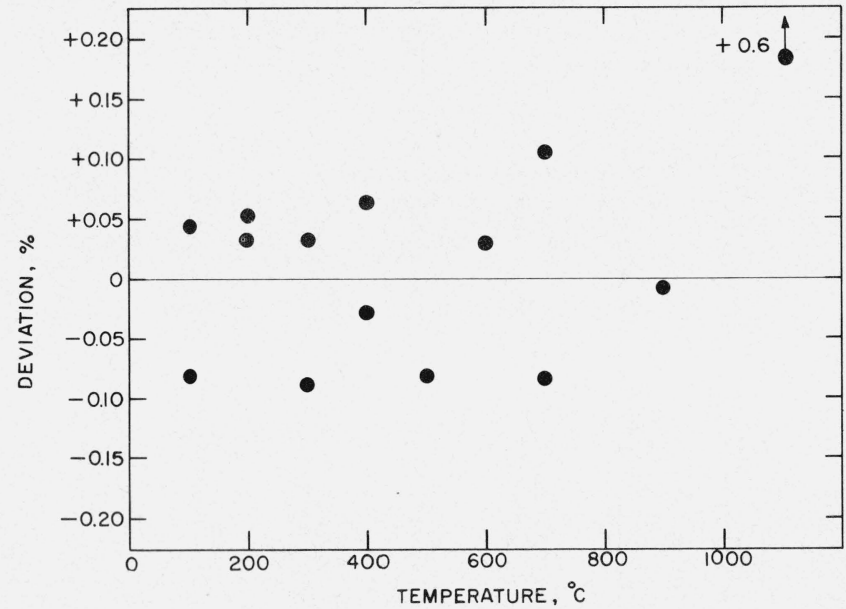

Figure 6. Percentage departures from eq (20) of the thermal conductivity data points obtained by the longitudinal heat flow method.
TABLE 3. Summary of individual uncertainties contributing to the overall uncertainty in the thermal conductivity results obtained using the longitudinal heat flow method

\begin{tabular}{l|c|c}
\hline \multirow{2}{*}{ Source of uncertainty } & \multicolumn{2}{|c}{ Uncertainty, \% } \\
\cline { 2 - 3 } & $100{ }^{\circ} \mathrm{C}$ & $900{ }^{\circ} \mathrm{C}$ \\
\hline Cross-sectional area & 0.02 & 0.02 \\
Heat flow & & \\
Power input to specimen & .05 & .05 \\
heater & .02 & .02 \\
Heat flow in current leads & .02 & .02 \\
Heat flow across neck & .3 & .6 \\
Heat loss into the insulation & .3 & .1 \\
Heat loss along thermocou- & & \\
ple wires and insulators & .2 & .02 \\
Departure from steady-state & .02 & .3 \\
Temperature gradient & .001 & .02 \\
Mean temperature & 0.5 & 0.7 \\
\hline Combined" & & \\
\hline
\end{tabular}

a Each combined uncertainty was obtained by taking the square root of the sum of the squares of the individual uncertainties.

obtained on heating and cooling in the first run and those from the second run. At $1100{ }^{\circ} \mathrm{C}$ the thermocouples started drifting giving rise to significant uncertainties in temperature measurement. After completing the "matched" gradient, "unmatched" gradient, and "isothermal" tests at $1100{ }^{\circ} \mathrm{C}$ a second "matched" gradient test was run. Two values for the thermal conductivity were obtained by simultaneous solution of each of the two "matched" gradient tests with the "isothermal" test. The first value $(0.820)$ was below the value predicted by $(20)$ and the second value $(0.905)$ was above it. Assuming that the temperature drifts were linear with time, interpolation to the time of the "isothermal" test gave a value of 0.866 for the thermal conductivity of the specimen at 1100 ${ }^{\circ} \mathrm{C}$. This value is 0.6 percent above the value given by extrapolation of $(20)$ to $1100{ }^{\circ} \mathrm{C}$. The $1100{ }^{\circ} \mathrm{C}$ point, due to the larger uncertainty associated with its value, was not used in deriving (20).

The thermal conductivity values corresponding to (20) are believed to be uncertain by not more than 1 percent over the temperature range 100 to $900{ }^{\circ} \mathrm{C}$. The estimated uncertainties arising from the various known sources of error are summarized in table 3; these uncertainies were discussed in section 4.2.

\section{Electrical Method}

\subsection{Experimental Procedure}

Measurements of thermal conductivity by the method in which the sample was heated directly by passage of an electric current were made following each measurement by the longitudinal heat flow method. Thus the preliminary procedures and testing sequence described in section 4.1 also apply to these measurements. Power to heaters $\mathrm{Q}_{1}$ and $\mathrm{Q}_{3}$ was controlled to maintain $T_{10}$ and $T_{11}$ constant with $\left|T_{11}-T_{10}\right|$ less than $0.2 \mathrm{deg}$. Temperatures along the guard in the region opposite the neck were maintained at the same value as $T_{10}$. Data were taken with currents (both normally and reversed) of approximately 10, 58, 82, and $100 \mathrm{~A}$ de flowing through the specimen. These 
current levels correspond approximately to even increments of power generation. Readings were taken of thermocouples 9, 10, 11, and 12 (see fig. 1) on the specimen and of the guard thermocouples between heaters $\mathrm{Q}_{5}$ and $\mathrm{Q}_{6}$. The voltage drops between the platinum legs of thermocouples 10 and 11 and also between 9 and 12 were measured with the current being measured simultaneously on another potentiometer.

The temperatures never drifted more than a few hundredths of a degree during a test (approximately three-quarters of an hour), and although the current showed drifts of 0.05 percent the measured resistances remained constant to 0.01 percent with current and voltage being read simultaneously.

\subsection{Calculation Procedures and Uncertainties}

Consider a conductor of arbitrary geometry which is perfectly insulated, both thermally and electrically, except for the ends where electric current enters and leaves the conductor. Joule heat will be generated in the conductor by the electric current. Let $T_{m}$ be the maximum temperature in the conductor. Let $V$ be the voltage drop between two surfaces, one on either side of the surface of maximum temperature, which are both at some lower temperature, $T_{0}$. It is shown in appendix C, where earlier work is referenced, that the following relation holds:

$$
\frac{V^{2}}{8}=\int_{T_{0}}^{T_{m}} \lambda \rho d T=\int_{0}^{{ }^{\theta} m} \lambda \rho d \theta
$$

where $\theta=T-T_{0}, \theta_{m}=T_{m}-T_{0}, \lambda$ is the thermal conductivity of the conductor, and $\rho$ is the electrical resistivity of the conductor.

Equation (21) shows that the maximum temperature rise, $\theta_{m}$, in an electrically heated conductor with negligible lateral heat losses and with both its uds held at the same temperature is a function only of the voltage drop $V$ across it, and of the thermal and electrical conductivities of the material, and is independent of the geometry of the conductor provided the geometry is such as to make lateral heat losses negligible. If the maximum temperature rise can be measured as a function of the applied potential, $\lambda \rho$ is readily determined.

The maximum temperature rise, $\theta_{m}$, can be measured indirectly using the specimen as its own resistance thermometer. This method was employed by Holm and Störmer [13] and Cutler et al. [15], and requires that the temperature coefficient of resistance of the material be known over the temperature range of interest and that it be large enough to yield sufficient sensitivity. Platinum satisfies both requirements very well and the resistance method of measuring the maximum temperature rise was adopted in the present experiments.

It is shown in appendix $\mathrm{C}$ that the following relation holds for a perfectly insulated conductor:

$$
\frac{R_{0}}{R}=\frac{1}{F} \int_{0}^{\theta_{m}} \frac{\lambda \rho_{0}\left(1+\gamma_{0} \theta\right) d \theta}{F},
$$

where

$$
F \equiv+\left\{2 \int_{0}^{A} \lambda \rho d \theta\right\}^{1 / 2}
$$

and $R$ is the electrical resistance between the two surfaces, one on either side of the surface of maximum temperature, which are both at the same temperature. $T$. The quantities $R_{0}$ and $\rho_{0}$ are the values $R$ and $\rho$ would have if the conductor were isothermal at some reference temperature, $T_{0}$. The quantity $\gamma_{0}$ is the coefficient of linear thermal expansion at $T_{0}$.

Assuming that $\lambda$ and $\rho$ can both be represented by linear functions of temperature - a valid assumption over small temperature intervals - we can write:

$$
\begin{gathered}
\rho=\rho_{0}\left(1+\alpha_{0} \theta\right), \\
\lambda=\lambda_{0}\left(1+\beta_{0} \theta\right), \\
\lambda \rho=\lambda_{0} \rho_{0}\left(1+\eta_{0} \theta\right) .
\end{gathered}
$$

where $\alpha_{0}$ is the temperature coefficient of resistance evaluated at $\theta=0, \beta_{0}$ is the temperature coefficient of thermal conductivity evaluated at $\theta=0$ and $\eta_{0}=\alpha_{0}$ $+\beta_{0}$. The term in $\alpha_{0} \beta_{0} \theta^{2}$ in (26) has been neglected. Substituting the above expression for $\lambda \rho$ into (23) and integrating we get

$$
F\left(\theta, \theta_{m}\right)+\left[2 \lambda_{0} \rho_{0}\left\{\theta_{m}\left(1+\frac{\eta_{0}}{2} \theta_{m}\right)-\theta\left(1+\frac{\eta_{0}}{2} \theta\right)\right\}\right]^{1 / 2}
$$

If the integration is evaluated for $T=T_{0}$, or $\theta=0$, we have, from (27) and (21),

$$
F=\left[2 \lambda_{0} \rho_{0} \theta_{m}\left(1+\frac{\eta_{0}}{2} \theta_{m}\right)\right]^{1 / 2}
$$

and

$$
V^{2}=8 \lambda_{0} \rho_{0} \theta_{m}\left(1+\frac{\eta_{0}}{2} \theta_{m}\right)
$$

Substituting $F$ from (27) into (22) and performing the indicated integration we have for $\theta=0$,

$$
\frac{R_{0}}{R}=\frac{\beta_{0}+\gamma_{0}}{\eta_{0}}+\frac{\alpha_{0}-\gamma_{0}}{\eta_{0}} \frac{1}{G} \arctan G,
$$

where

$$
G^{2} \equiv 2 \eta_{0} \theta_{m}\left(1+\frac{\eta_{0}}{2} \theta_{m}\right) .
$$

The coefficients $\alpha_{0}$ and $\beta_{0}$ are the "true" coefficients in that they correspond to electrical resistivity and thermal conductivity values which have been corrected for thermal expansion. If one considers "apparent" coefficients $\alpha_{0}^{\prime}$ and $\beta_{0}^{\prime}$ which correspond to "apparent" thermal conductivity values which have not been 
corrected for thermal expansion, then it is apparent that $\alpha_{0}=\alpha_{0}^{\prime}+\gamma_{0}, \beta_{0}=\beta_{0}^{\prime}-\gamma_{0}, \eta_{0}=\eta_{0}^{\prime}$, and (30) can be written as

$$
\frac{R_{0}}{R}=\frac{\beta_{0}^{\prime}}{\eta_{0}^{\prime}}+\frac{\alpha_{0}^{\prime}}{\eta_{0}^{\prime}} \frac{1}{G} \arctan G,
$$

where, reiterating, $\alpha_{0}^{\prime}, \beta_{0}^{\prime}$, and $\eta_{0}^{\prime}=\alpha_{0}^{\prime}+\beta_{0}^{\prime}$ are apparent coefficients corresponding to electrical resistivity and thermal conductivity values which have not been corrected for thermal expansion. Thus the maximum temperature rise in the conductor can be computed without knowing the coefficient of expansion.

Equation (30) gives $\theta_{m}$ implicitly in terms of known measured parameters, and its value can be determined by iteration. In practice it would generally be necessary to measure $R$ at at least two different levels of heating current and then extrapolate to zero current to obtain $R_{0}$. Once $\theta_{m}$ is obtained using (30), its value can be used in conjunction with (29) to obtain the thermal conductivity. In the present investigation, $R$ and $V$ were measured at four or five different current levels. The data obtained were analyzed as described below.

An adjusted voltage, $V^{*}$, was defined as:

$$
V^{* 2}=\frac{V^{2}}{1+\frac{\eta_{0}}{2} \theta_{m}} .
$$

In the limit of small $\alpha_{0} \theta_{m}$, (30) reduces to

$$
\frac{R-R_{0}}{\alpha_{0} R_{0}}=\frac{2}{3} \theta_{m} .
$$

An adjusted resistance, $R^{*}$, was defined for the case where $\alpha_{0} \theta_{m}$ is not sufficiently small for (34) to be valid:

$$
R^{*}=R_{0}\left(1+\frac{2}{3} \alpha_{0} \theta_{m}\right)
$$

In the limiting case of small $\alpha_{0} \theta_{m}$, (35) reduces to (34) and $R^{*}$ to $R$.

Substituting (33) and (35) into (29), we obtain

$$
V^{* 2}=12 \lambda_{0} \rho_{0} \frac{R^{*}-R_{0}}{\alpha_{0} R_{0}} .
$$

Differentiating (36) and rearranging, we obtain

$$
\lambda_{0}=\frac{\alpha_{0} R_{0}}{12 \rho_{0}} \frac{d V^{* 2}}{d R^{*}} .
$$

The thermal conductivity values in the electrical method were obtained from the slope of the $V^{* 2}$ versus $R^{*}$ curve, using (37). From (33) and (35) we see that

$$
\frac{d V^{* 2}}{d R^{*}}=\operatorname{Lim}_{\alpha_{1} \theta_{m} \rightarrow 0} \frac{d V^{2}}{d R} .
$$

In the analysis given in appendix $\mathrm{C}$ and also that given just above, we explicitly assumed that there was no loss or gain of either electric current or heat across the surface of the conductor. In the present investigation a necked-down sample was employed, the neck and the specimen as a whole being surrounded by an insulating powder. Since this insulating powder had an electrical conductivity many orders of magnitude lower than that of the specimen material, the assumption of no flow of electric current across the boundaries was completely valid. The powder surrounding the neck prevented heat loss by convection, and radiation through the powder was negligible. However, the powder conducted heat away from the neck and it was necessary to analyze this heat loss and develop an appropriate correction for it. Since most of the temperature rise between thermocouple positions 10 and 11 was in the neck itself, only heat losses from the neck were considered and other heat exchanges were neglected. O'Hagan [9] has shown that in the presence of small heat losses from the neck, (37) is replaced by

$$
\lambda_{0}=\frac{1}{1+C} \frac{\alpha_{0} R_{0}}{12 \rho_{0}} \frac{d V^{* 2}}{d R^{*}},
$$

where

$$
C=\frac{\kappa_{0}}{\lambda_{0}} \Omega
$$

$\kappa_{0}$ being the thermal conductivity of the powder insulation at the reference temperature, $T_{0}$, and $\lambda_{0}$ the thermal conductivity of the specimen at $T_{0}$. The geometrical factor, $\Omega$, is given by

$$
\Omega=\frac{64}{\pi^{3} a^{2}}\left(\frac{2 l}{\pi a}\right)^{3} \frac{K_{1}(\pi a / 2 l)}{K_{0}(\pi a / 2 l)} \frac{\rho_{0}^{2}}{R_{0}^{2}},
$$

where $2 a$ is the diameter of the neck and $2 l$ is the length of the neck, and $K_{0}$ and $K_{1}$ are the modified Bessel functions of second kind and order zero and one, respectively.

The calculation procedure used was as follows: At any given nominal temperature, measurements were made at $n$ current levels. An approximate value for $R_{0}$ was computed from the resistance corresponding to the lowest current level, for which Joule heating was minimal and the neck was nearly isothermal. For each experimentally determined resistance a corresponding approximate value of $\theta_{m}$ was computed using (34). Values of $\alpha_{0}^{\prime}$ were computed from the data obtained in the resistivity measurements (see sec. 5.3a). Using this value of $\theta_{m}$ as the first trial value, Newton-Raphson iteration was used to compute the value of $\theta_{m}$ which satisfied $(30){ }^{4}$ Values for $R^{*}$ and $V^{* 2}$ were then computed from (35) and (33) respectively. Since it was impractical to hold $T_{0}$ (i.e., the average temperature of thermo-

${ }^{4}$ Values for $\beta_{0}^{\prime}$ computed from the thermal conductivity values obtained by $\mathrm{W}$ atson and Flynn [32] on the same specimen were used. 
couple locations 10 and 11) at exactly the same value for different current settings, it was necessary to adjust slightly the $V^{* 2}$ and $R^{*}$ values to correspond to a common reference temperature. A straight line of least-squares fit through these values of $R^{*}$ and $V^{* 2}$ gave $R_{0}$ as the ordinate intercept and $d V^{* 2} / d R^{*}$ as the slope. This value for $R_{0}$ was a more accurate value than the initial value used, as it was based on an extrapolation to $I=0$. The calculation was then repeated using this value of $R_{0}$. This in turn led to improved values for $R_{0}$ and $d V^{* 2} / d R^{*}$. The iteration converged in a few passes and the final values for $R_{0}$ and $d V^{* 2} / d R^{*}$ were used in (37) to compute the apparent thermal conductivity. Using this apparent value for $\lambda_{0}$, and eqs (40) and (41), the correction factor for heat losses from the neck was computed and used in (39) to give the final value for the thermal conductivity.

\section{a. Electrical Resistivity}

The electrical resistivity values were computed from

$$
\rho_{0}=\rho_{\text {ice }} R_{0} /\left(R_{0}\right)_{\text {ice }},
$$

where $\rho_{\text {ice }}$ is the independently measured ice-point resistivity, $R_{0}$ is the resistance of the necked-down region at zero current, and $\left(R_{0}\right)_{\text {ice }}$ is the value of $R_{0}$ extrapolated to the ice point. These values were then corrected for thermal expansion. The uncertainty in $\rho_{\text {ice }}$ was not more than 0.1 percent. The uncertainties in the measured values of $R_{0}$ did not exceed 0.05 percent. However, an additional uncertainty must be assigned to the values of $R_{0}$ due to the uncertainty in the temperature to which these values correspond. Quite conservatively, temperatures were known to within $0.5 \mathrm{deg}$, corresponding to 0.14 percent of $R_{0}$ at $100{ }^{\circ} \mathrm{C}$ and 0.04 percent at $900{ }^{\circ} \mathrm{C}$. The uncertainty in $\left(R_{0}\right)_{\text {ice, }}$, which was based on an extrapolation, was estimated to be less than 0.25 percent. At lower temperatures the uncertainties in $R_{0}$ were correlated with the uncertainty in $\left(R_{0}\right)_{\text {ice }}$ so that the uncertainties in $R_{0} /\left(R_{0}\right)_{\text {ice }}$ were lower than the uncertainties in either $R_{0}$ or $\left(R_{0}\right)_{\text {ice }}$ at lower temperatures but not necessarily at higher temperatures. The overall uncertainty in electrical resistivity was estimated to be less than 0.1 percent at $0{ }^{\circ} \mathrm{C}$ and less than 0.4 percent at $900{ }^{\circ} \mathrm{C}$.

The thermal conductivity was computed, using (39), from the ratio $R_{0} / \rho_{0}$. Since $\rho_{0}$ was taken from a smoothed curve, this quantity was further uncertain by the scatter in the individual $R_{0}$ data points around a smooth curve, or about an additional 0.05 percent (see sec. 5.3a). The overall uncertainty in $R_{0} / \rho_{0}$ was probably less than 0.4 percent.

\section{b. Temperature Coefficient of Resistance}

The uncertainty in the sensitivity, $\alpha_{0}$, of the specimen as a resistance thermometer was essentially the uncertainty in the sensitivity of the thermocouples used plus a small uncertainty in the resistance measurements and the thermocouple emf measurements.
That this is so is seen by considering that $R_{0}$ was measured as a function, say $R_{0}=f(E)$, of the thermocouple emf, E. Then

$$
\alpha_{0}=\frac{1}{R_{0}} \frac{d R_{0}}{d T}=\frac{1}{f(E)} \frac{d f(E)}{d E} \frac{d E}{d T} \equiv g(E) \frac{d E}{d T} .
$$

The uncertainty in the sensitivity, $d E / d T$, of the thermocouples is estimated to have been less than 0.2 percent while the uncertainty in the resistance and voltage measurements was less than 0.05 percent. Thus $\alpha_{0}$ is believed to have been known with an uncertainty of less than 0.25 percent.

\section{c. Slope of $V^{* 2}$ Versus $R^{*}$ Curve}

The voltage drop across the neck and the resistance of the neck were each measured with an uncertainty of about 0.02 percent. The change in the resistance of the neck for the different current levels was small compared to the resistance itself, so that any error in measuring resistance would be greatly magnified in computing the rate of change of resistance as a function of the voltage drop. For all of the data taken, the departures of the $R^{*}$ values from the least-squares straight line fitted to the $R^{*}$ and $V^{* 2}$ values were less than 0.01 percent and for a majority of the tests they were less than 0.005 percent. However, since $\left(R-R_{0}\right)$ $\ll R$, the small scatter in $R$ was highly magnified in calculating $d V^{* 2} / d R^{*}$. What departures did exist tended to be systematic rather than random and tended to indicate that the plot of $R^{*}$ versus $V^{* 2}$ was very slightly concave downward rather than linear, as assumed. Such an effect could possibly have been due to neglecting higher order terms in the temperature dependence of the thermal conductivity and the electrical resistivity. The uncertainty in $d V^{* 2} / d R^{*}$ is estimated to have been less than 1.5 percent.

\section{d. Heat Loss Correction}

The uncertainty in the heat loss correction, $C$, may have been as large as 50 percent of $C$. For the tests in argon this corresponds to an uncertainty in the measured values for the thermal conductivity of the specimen of 0.1 percent at $100{ }^{\circ} \mathrm{C}$ and 0.6 percent at $900^{\circ} \mathrm{C}$. For the tests in helium the corresponding uncertainties were 0.5 percent at $200{ }^{\circ} \mathrm{C}$ and 0.7 percent at $400{ }^{\circ} \mathrm{C}$.

\section{e. Departures From Theory}

In the derivation of the mathematical expressions used to compute thermal onductivity in the electrical method, there were a number of explicit or implicit assumptions made which ce lead to erroneous results if these assumptions were not valid.

It is shown in appendix $\mathrm{C}$ that the Thomson effect cancels out to first order provided the temperatures at the two potential taps (used to measure $V$ ) are approximately the same. The requirement that the potential taps be at the same temperature is also necessary for the Seebeck emf and Fermi energy terms in $(\mathrm{C}-50)$ to drop out. In all of the measure- 
ments, the temperatures at the inner potential taps (thermocouple positions 10 and 11) agreed within 0.2 deg or better, as compared with values of $\theta_{m}$ (for 100 A current) ranging from $35 \mathrm{deg}$ at $100{ }^{\circ} \mathrm{C}$ to $100 \mathrm{deg}$ at the highest temperatures. Neglecting the Seebeck term in $(\mathrm{C}-50)$ for $\left|T_{2}-T_{1}\right|<0.2 \mathrm{deg}$ corresponds to an uncertainty in the measured thermal conductivity values of less than 0.05 percent. Neglecting the Fermi energy term in $(\mathrm{C}-50)$ also involves an uncertainty of less than 0.05 percent (see O'Hagan [9, p. 127]).

It is explicitly assumed in appendix $\mathrm{C}$ that the conductor is homogeneous and isotropic; this should be a valid assumption for platinum of the purity used in the present investigation.

As stated in appendix $\mathrm{C}$, the electron current is considered to be the only mass current. In principle it would be possible for platinum, or any impurities which might be present, to migrate under the influence of the electric potential gradient (electromigration) or under the influence of the temperature gradient (Soret effect). If such mass motion existed there would be an associated entropy flow and equation $(\mathrm{C}-4)$ and all following equations in appendix $\mathrm{C}$ would have to be modified to include a term involving the mass current density and its associated entropy transport. A rigorous analysis including mass migration would be quite complex and was felt to be beyond the scope of the present investigation. However, a qualitative discussion of the probable effect of such mass motion if it were to occur is given below.

In electromigration, the energy flow is proportional to the electric field. Similarly, the energy flow due to the Thomson effect is essentially proportional to the electric field. Thus if one were to introduce an electromigration term into $(\mathrm{C}-4)$ and rigorously go through the analysis, the equivalent expression to $(\mathrm{C}-31)$ would include an electromigration term of a form analogous to (i.e., proportional to the electric field) the term in $(\mathrm{C}-31)$ involving the Thomson coefficient. Provided this term were small compared with the first two terms in (C-35) it would, to first order, cancel in a similar manner to the way the Thomson term canceled, provided the temperature at the two potential taps were the same and the medium was homogeneous and isotropic. Physically what happens is that the energy transport due to electromigration adds to the energy transport by conduction on one side of the surface of maximum temperature and subtracts on the other side, with no net effect on the maximum temperature rise in the conductor or on the voltage drop between the potential taps, at least to first order. To reemphasize, the temperatures at the taps must be the same for this cancellation to occur and also the medium must be homogeneous and isotropic.

In the Soret effect, the energy transport is proportional to the temperature gradient. Thus the ratio of energy transport due to the Soret effect to that due to heat conduction by other mechanisms is independent of the temperature gradient. The Soret effect is a diffusion process, similar to heat conduction. For a homogeneous medium, therefore, the Soret effect simply behaves as an additional mechanism for "heat conduction" and thus is a legitimate augmentation (or depletion, depending on the sign of the heat of transport) of the thermal conductivity and should be included in the total thermal conductivity value.

For the conditions of the present experiments, there would be no errors involved due to electromigration or Soret effect provided the medium remained homogeneous and isotropic. Both of these effects can change the distribution of impurities and vacancies in a solid. During the experiments the current was in one direction through the specimen about one-half of the time and in the other direction about one-half of the time. Thus, it is doubtful if there was significant inhomogenity introduced due to electromigration effects, even if they were occurring. The Soret effect, if large enough, could cause a redistribution of impurities in the specimen.

For platinum of the purity used, the thermal conductivity at high temperatures would not be expected to be significantly affected by changes in the impurity and vacancy distribution. All of the data at low temperatures, where impurity concentration could affect the thermal conductivity, were taken before the specimen was heated to temperatures where significant mass migration was likely to occur. In view of the above discussion it is felt that neither electromigration nor Soret effect had any adverse effect on the results.

\subsection{Results}

a. Electrical Resistivity

The ice-point resistivity was determined on the platinum bar before the neck was machined in it (see section 2). The value obtained was

$$
\left(\rho_{0}\right)_{\text {ice }}=9.847 \pm 0.010 \mu \Omega \mathrm{cm},
$$

corrected to $0{ }^{\circ} \mathrm{C}$ dimensions.

In conjunction with the electrical method of measuring thermal conductivity, the resistance of the necked-down region of the specimen at each temperature was determined at a number of current levels. The resistance, $R_{0}$, at temperature $T_{0}$, was evaluated by extrapolation to zero current as described in section 5.2. In the first series of tests, or the first run as it will be referred to, measurements were made in the following order: 100, 300, 500, 700, 600, 400, and $200{ }^{\circ} \mathrm{C}$ in argon; and 200 and $400{ }^{\circ} \mathrm{C}$ in helium. The apparatus was then opened up for repair of the guard heater as described in section 4.1c. In the second series of tests, or the second run as it will be referred to, measurements were made at 300, 700, 900, and $1100{ }^{\circ} \mathrm{C}$ in argon, in that order.

The values for the resistance of the neck obtained during the second run were about 1.5 percent higher than the values obtained at corresponding temperatures in the first run. This increase in resistance was observed both for measurements at the inner potential taps $(10,11)$ and for measurements at the outer potential taps $(9,12)$, indicating that the increase in values 
were due either to contamination or to a change in the geometrical factor of the necked-down region rather than to, for example, a short circuit which changed the effective position of one of the potential taps. Since data taken in the first run at lower temperatures after the sample had been heated to $700{ }^{\circ} \mathrm{C}$ agreed quite closely with results obtained before the sample was heated to $700{ }^{\circ} \mathrm{C}$, it is felt that there was no evidence indicating that any chemical contamination of the necked-down region occurred during the first run. Furthermore, $700{ }^{\circ} \mathrm{C}$ is rather too low a temperature to expect any significant contamination of platinum in a relatively clean environment. Exactly what happened is not known but it is believed that the necked-down region suffered some slight geometrical change between the first and second runs, perhaps while the guard heater was being repaired. In determining the electrical resistivity, data from the first run had to be treated separately in view of this change in the geometric factor.

A quadratic equation was fitted, by the method of least squares, to the measured values of $R_{0}$ from the tests in air, argon, and helium from the first run. The equation, extrapolated to $0{ }^{\circ} \mathrm{C}$ and normalized to the ice-point resistivity, (44), gave

$\rho=9.847\left(1+0.3963 \times 10^{-2} t-0.5389 \times 10^{-6} t^{2}\right)$

as the electrical resistivity (corrected for thermal expansion) of the neck from 0 to $700{ }^{\circ} \mathrm{C}, t$ being in ${ }^{\circ} \mathrm{C}$ and $\rho$ in $\mu \Omega \mathrm{cm}$. The standard deviation of the residuals from this equation was 0.03 percent. Departures of the data points from this equation are plotted in figure 7 where the overall scatter is seen to be \pm 0.05 percent. All but three of the points fall within 0.025 percent of the curve and there is no significant difference between the values obtained on heating and cooling.

A second quadratic equation was fitted to the data points (corrected for thermal expansion) at 300, 700,

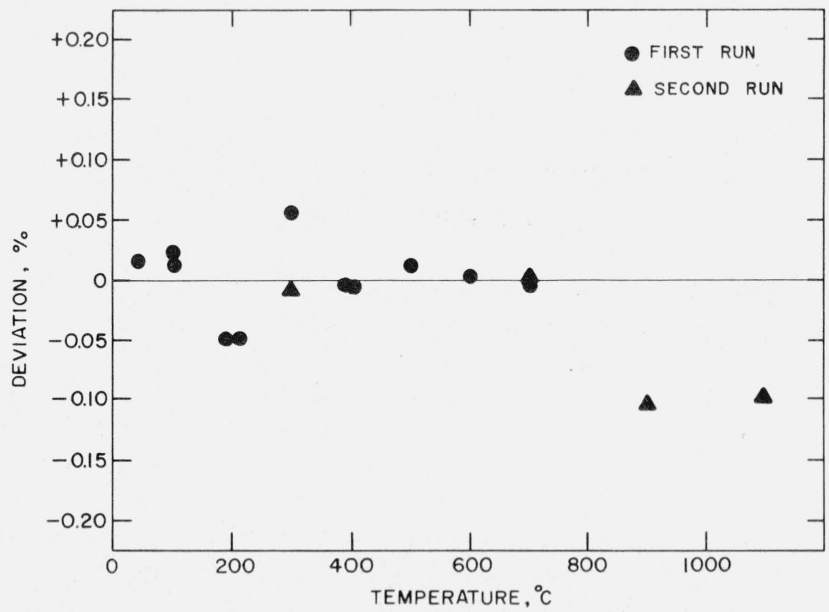

Figure 7. Percentage departures from eq (45) of the electrical resistivity data points.

The values obtained during the second run have been normalized at $700{ }^{\circ} \mathrm{C}$ as discussed in the text. and $900{ }^{\circ} \mathrm{C}$ obtained in the second run. The equation, normalized to the value given by $(45)$ at $700{ }^{\circ} \mathrm{C}$, gave

$\rho=9.767\left(1+0.4033 \times 10^{-2} t-0.5802 \times 10^{-6} t^{2}\right)$,

$t$ being in ${ }^{\circ} \mathrm{C}$ and $\rho$ in $\mu \Omega \mathrm{cm}$. While the geometric factor of the neck changed between the first and second runs there is no reason to believe the resistivity would have changed. Any strains introduced when the geometric factor changed would have annealed out at $700{ }^{\circ} \mathrm{C}$. Thus normalizing the data from the second run to that from the first run at $700{ }^{\circ} \mathrm{C}$ is felt to be justified. The departures of the normalized data points at $300,700,900$, and $1100{ }^{\circ} \mathrm{C}$ from the values given by eq (45) are indicated by triangles in figure 7 . The 1100 ${ }^{\circ} \mathrm{C}$ data point was not used in deriving (46). The thermocouples started to drift at $1100{ }^{\circ} \mathrm{C}$ due to contamination so that greater uncertainty had to be assigned to data obtained at that temperature. The $1100{ }^{\circ} \mathrm{C}$ data point agrees with the extrapolated value given by equation (46) to within 0.02 percent. The deviations from the quadratic equation (45) at the higher temperatures as shown in figure 7 are in line with what one would expect. Recent measurements at NBS [29] in conjunction with work toward extending platinum resistance thermometry to the gold point showed that the measured resistance of a certain high purity platinum resistance thermometer at the gold point $\left(1063^{\circ} \mathrm{C}\right)$ was about 0.07 percent below the value obtained by extrapolating the Callendar equation [5] for that thermometer from $630.5{ }^{\circ} \mathrm{C}$ to the gold point $\left(1063{ }^{\circ} \mathrm{C}\right)$. Laubitz and van der Meer [30], in measuring the electrical resistivity of high purity $(99.999 \%$ pure $)$ platinum, found that between 800 and $1200{ }^{\circ} \mathrm{C}$ their experimental results fell consistently below the values extrapolated from an equation similar to (45) by an average amount of 0.10 percent.

As stated in section $5.2 \mathrm{a}$, the uncertainty in the electrical resistivity values is estimated to be less than 0.1 percent at $0{ }^{\circ} \mathrm{C}$ and less than 0.4 percent at $900{ }^{\circ} \mathrm{C}$.

\section{b. Thermal Conductivity}

The experimental values obtained for the thermal conductivity of the platinum sample by the electrical method are given in table 4 . The values for $\rho_{0}$ and $\alpha_{0}$ used in computing these thermal conductivity values were computed using (45) in the first run and (46) in the second run. The thermal conductivity values given in table 4 have been corrected for thermal expansion. A typical set of data is given in table 5 .

The following equation, obtained by the method of least squares, was found to fit the thermal conductivity data (corrected for thermal expansion) obtained in air and in argon, using the electrical method, with a standard deviation of 0.30 percent:

$\lambda=0.716-0.247 \times 10^{-5} t+0.182 \times 10^{-6} t^{2}$

$$
-0.783 \times 10^{-10} t^{3},
$$

where $t$ is temperature in ${ }^{\circ} \mathrm{C}$ and $\lambda$ is in $\mathrm{W} / \mathrm{cm} \mathrm{deg}$. 
TABLE 4. Experimental values for the thermal conductivity of platinum as measured using the electrical method The values given are corrected for thermal expansion.

\begin{tabular}{l|r|l|r|r}
\hline \hline Test & Run & Atmosphere & $\begin{array}{c}\text { Mean } \\
\text { temperature } \\
{ }^{\circ} \mathrm{C}\end{array}$ & $\begin{array}{c}\text { Thermal } \\
\text { conductivity } \\
\text { W/cm deg }\end{array}$ \\
\hline & & & 99.8 & 0.719 \\
1 & 1 & Air & 99.7 & .716 \\
2 & 1 & Argon & 299.9 & .732 \\
3 & 1 & Argon & 500.0 & .749 \\
4 & 1 & Argon & 700.1 & .779 \\
5 & 1 & Argon & 599.6 & .763 \\
6 & 1 & Argon & 400.3 & .738 \\
7 & 1 & Argon & 202.0 & .720 \\
8 & 1 & Argon & 199.9 & .722 \\
9 & 1 & Helium & 400.2 & .745 \\
10 & 1 & Helium & 300.1 & .731 \\
11 & 2 & Argon & 699.9 & .774 \\
12 & 2 & Argon & 900.0 & .804 \\
13 & 2 & Argon & &
\end{tabular}

TABLE 5. Typical set of data from measurements of the thermal conductivity of platinum by the electrical method The data correspond to Test No. 6 in table 4.

\begin{tabular}{|c|c|c|c|c|}
\hline $\begin{array}{l}\text { Heating current through necked- } \\
\text { down region....................... I }\end{array}$ & 10.0 & 57.6 & 81.7 & 100.1 \\
\hline $\begin{array}{l}\text { Average temperature at thermo- } \\
\text { couple locations } 10 \text { and } 11 \ldots . .{ }^{\circ} \mathrm{C} \ldots T_{0}\end{array}$ & 599.5 & 599.6 & 599.6 & 599.6 \\
\hline 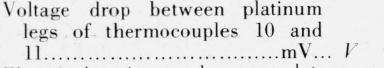 & 12.03 & 70.80 & 102.14 & 127.52 \\
\hline $\begin{array}{l}\text { Electrical resistance between plat- } \\
\text { inum legs of thermocouples } 10 \\
\text { and } 11 \ldots \ldots \ldots \ldots \ldots \ldots \ldots \ldots \ldots \ldots \ldots \ldots \\
\end{array}$ & 1.2086 & 1.2290 & 1.2509 & 1.2734 \\
\hline $\begin{array}{l}\text { Calculated temperature rise in } \\
\text { necked-down region............deg... } \theta_{m}\end{array}$ & 0.8 & 25.5 & 52.2 & 80.2 \\
\hline 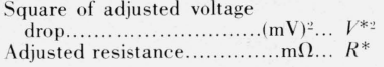 & $\begin{array}{l}145 . \\
1.2086\end{array}$ & $\begin{array}{l}4930 . \\
1.2292\end{array}$ & $\begin{array}{r}10090 . \\
1.2513\end{array}$ & $\begin{array}{l}15456 . \\
\quad 1.2746\end{array}$ \\
\hline
\end{tabular}

\begin{tabular}{|c|c|c|}
\hline Reference temperature.......... ${ }^{\circ} \mathrm{C} \ldots$ & $T_{0}$ & 599.6 \\
\hline $\begin{array}{l}\text { Electrical resistivity at reference } \\
\text { temperature............. } \mu \Omega \mathrm{cm} . .\end{array}$ & $\rho_{0}$ & 31.16 \\
\hline $\begin{array}{l}\text { Electrical resistance corresponding } \\
\text { to reference temperature...m } \Omega \text {... }\end{array}$ & $R_{0}$ & 1.2079 \\
\hline $\begin{array}{l}\text { Temperature coefficient of } \\
\text { resistivity at reference tem- } \\
\text { perature........................... }\end{array}$ & $\alpha_{0}$ & 0.001032 \\
\hline 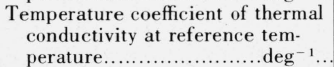 & $\beta_{0}$ & 0.000267 \\
\hline Correction for heat loss.................. & $C$ & 0.0077 \\
\hline $\begin{array}{l}\text { Correction for thermal expan- } \\
\text { sion.........................percent... }\end{array}$ & & 0.56 \\
\hline $\begin{array}{l}\text { Computed value for thermal } \\
\text { conductivity of speci- } \\
\text { men...................W } / \mathrm{cm} \mathrm{deg..}\end{array}$ & $\lambda_{0}$ & 0.763 \\
\hline
\end{tabular}

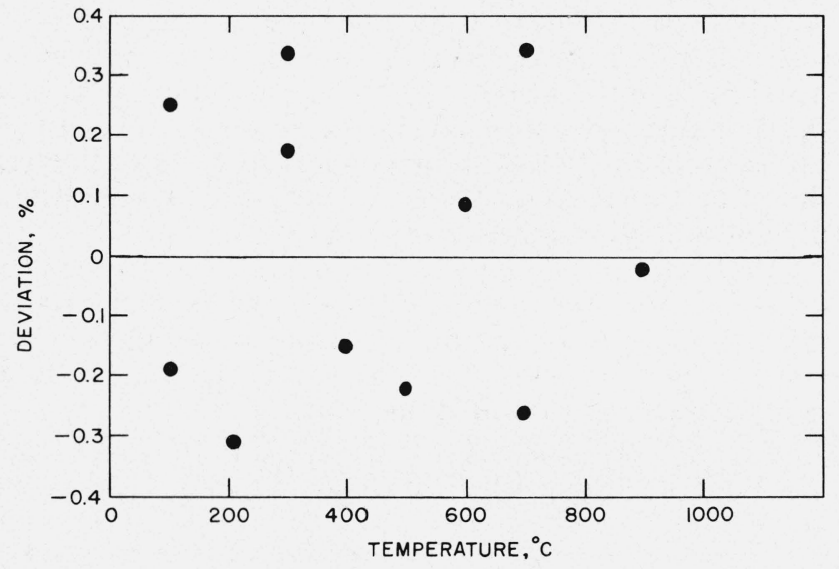

Figure 8. Percentage departures from eq (47) of the thermal conductivity data points obtained by the electrical method.
This equation is valid from 100 to $900{ }^{\circ} \mathrm{C}$. Deviations of the data points from eq (47) are plotted in figure 8 . The scatter is random and there are no significant differences between values obtained on heating and cooling or between the first run and the second run. The value obtained in helium at $200{ }^{\circ} \mathrm{C}$ agrees within 0.05 percent of the value given by (47) but the measurement in helium at $400{ }^{\circ} \mathrm{C}$ shows a deviation of +0.9 percent. The measurements in helium were made during the first run and there is a possibility that the powder insulation did not uniformly and completely fill the necked-down region. If the powder did not completely fill the space, the boundary conditions assumed in deriving the heat loss corrections would not have been met. Any errors in the heat loss correction would be amplified in helium, particularly at the higher temperature, due to the high thermal conductivity of this gas. In the second run the powder was carefully packed around the neck so that the neckeddown region was completely and uniformly filled with insulation. The two data points obtained in helium were not used in deriving (47).

The thermal conductivity values corresponding to (47) are believed to be uncertain by not more than 2 percent over the temperature range 100 to $900{ }^{\circ} \mathrm{C}$. The estimated uncertainties arising from the various known sources of error are summarized in table 6; these uncertainties were discussed in section 5.2.

TABLE 6. Summary of individual uncertainties contributing to the overall uncertainty in the thermal conductivity results obtained using the electrical method

\begin{tabular}{l|c|c}
\hline \hline \multirow{2}{*}{ Source of uncertainty } & \multicolumn{2}{|c}{ Uncertainty, \% } \\
\cline { 2 - 3 } & $100{ }^{\circ} \mathrm{C}$ & $900{ }^{\circ} \mathrm{C}$ \\
\hline Geometrical factor $\left(R_{0} / \rho_{0}\right)$ & 0.4 & 0.4 \\
Temperature coefficient of resistance & .25 & .25 \\
Slope of $V^{* 2}$ versus $R^{*}$ curve & 1.5 & 1.5 \\
Heat loss correction (tests in argon) & .1 & .6 \\
Seebeck effect & .05 & .05 \\
Temperature coefficient of Fermi energy & .05 & .05 \\
\hline Combined & 1.6 & 1.7 \\
\hline
\end{tabular}

a Each combined uncertainty was obtained by taking the square root of the sum of the squares of the individual uncertainties.

\section{Comparison of Results With Other Investigations}

The smoothed experimental results given in sections 4.3 and 5.3 are tabulated in table 7 . The electrical resistivity values correspond to equation (45) from 0 to $700{ }^{\circ} \mathrm{C}$ and to $(46)$ at 800 and $900{ }^{\circ} \mathrm{C}$. The thermal conductivity values for the longitudinal heat flow method and the electrical method correspond to eqs (20) and (47), respectively. The values for the Lorenz function, $\lambda \rho / T$, were computed from the smoothed values for the electrical resistivity, $\rho$, the two sets of values for thermal conductivity, $\lambda$, and the absolute temperature, $T$.

In this section the results of other investigations on platinum are compared with the results of the present 
investigation. Since many investigators do not correct their thermal conductivity and electrical resistivity results for thermal expansion, it was necessary to convert all data to a common basis in order to make valid comparisons.

TABLE 7. Smoothed experimental values for thermal conductivity, electrical resistivity, and Lorenz function of platinum All values are corrected for thermal expansion.

\begin{tabular}{|c|c|c|c|c|c|}
\hline \multirow{2}{*}{$\begin{array}{c}\text { Tem- } \\
\text { pera- } \\
\text { ture } \\
{ }^{\circ} \mathrm{C}\end{array}$} & \multirow{2}{*}{$\begin{array}{c}\text { Electrical } \\
\text { resistivity } \\
\mu \Omega \mathrm{cm}\end{array}$} & \multicolumn{2}{|c|}{$\begin{array}{c}\text { Thermal conductivity } \\
\mathrm{W} / \mathrm{cm} \text { deg }\end{array}$} & \multicolumn{2}{|c|}{$\begin{array}{l}\text { Lorenz function } \\
V^{2} / \operatorname{deg}^{2}\end{array}$} \\
\hline & & $\begin{array}{l}\text { Longitu- } \\
\text { dinal } \\
\text { method }\end{array}$ & $\begin{array}{l}\text { Electrical } \\
\text { method }\end{array}$ & $\begin{array}{l}\text { Longitudinal } \\
\text { method }\end{array}$ & $\begin{array}{l}\text { Electrical } \\
\text { method }\end{array}$ \\
\hline 0 & 9.847 & & & & \\
\hline 100 & 13.70 & 0.715 & 0.717 & $2.62 \times 10^{-8}$ & $2.63 \times 10^{-8}$ \\
\hline 200 & 17.44 & .721 & .722 & 2.66 & 2.66 \\
\hline 300 & 21.08 & .729 & .729 & 2.68 & 2.68 \\
\hline 400 & 24.61 & .740 & .739 & 2.70 & 2.70 \\
\hline 500 & 28.03 & .753 & .750 & 2.73 & 2.72 \\
\hline 600 & 31.35 & .768 & .763 & 2.76 & 2.74 \\
\hline 700 & 34.56 & .785 & .776 & 2.79 & 2.76 \\
\hline 800 & 37.65 & .803 & .790 & 2.82 & 2.77 \\
\hline 900 & 40.63 & .822 & .804 & 2.85 & 2.78 \\
\hline
\end{tabular}
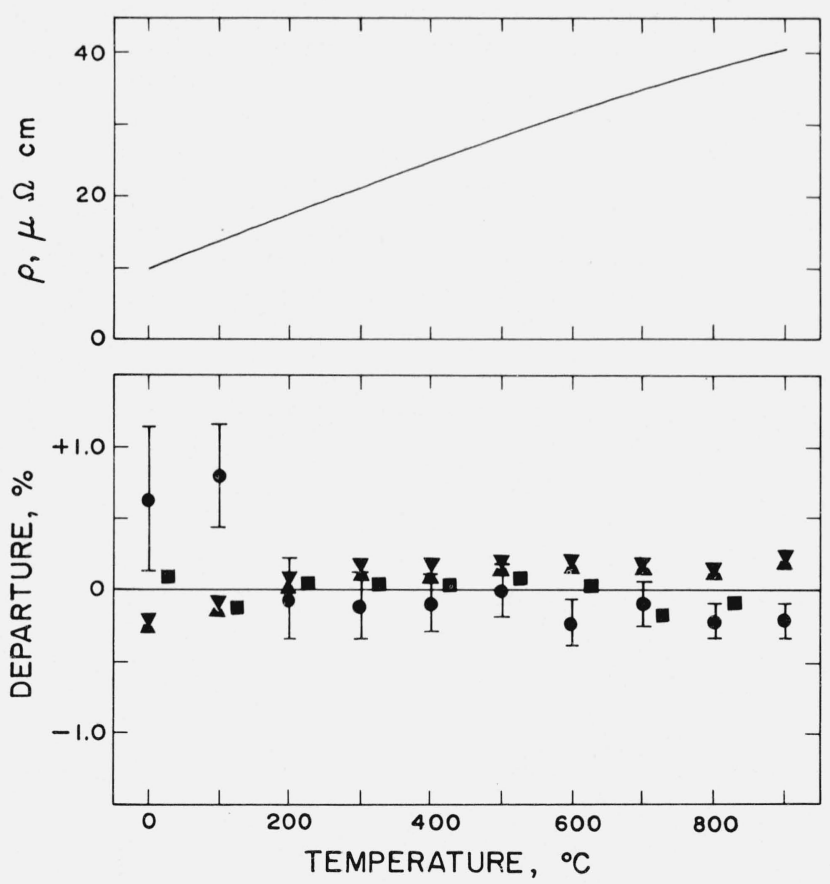

Figure 9. Electrical resistivity of platinum: comparison of previous data with the results of the present investigation.

Powell and Tye [1]. Reported purity was 99.999 percent for both samples tested. The ratio of the ice point to helium point resistivity of their No. 1 specimen, which was purer than their No. 2 specimen, was previously reported by Powell. Tye, and Woodman [11] to be about 760 . The uncertainties shown represent possible round-off error due to TII to be about 60. . The uncertainties shown repres

\ Laubitz and van der Meer $|30|$. The reported purity was 99.999 percent. The ratio of ice point to helium point resistivity was about 1890 .

Roeser [31]. His sample was probably thermometric grade platinum having a purity of about 99.999 percent

Martin, Sidles, and Danielson [37]. The values shown correspond to their sample which had a reported purity of 99.999 percent and a ratio of ice point to helium point resistiv. ity of 5000 .

\subsection{Electrical Resistivity}

The electrical resistivity values reported for platinum by Powell and Tye [1], Laubitz and van der Meer [30], Roeser [31], and Martin, Sidles, and Danielson [37] are compared with the results of the present investigation in figure 9. The reported purities and resistivity ratios for the different samples are given in the figure caption.

\subsection{Thermal Conductivity}

The thermal conductivity values reported for platinum by Powell and Tye [1], Laubitz and van der Meer [30], and Martin, Sidles, and Danielson [37, 60] are compared with the results of the present investigation in figure 10. The base line in this figure is a weighted average of the two sets of data obtained in the present investigation, the data from the longitudinal heat flow method being given twice the weight that was given to the data from the electrical method, which had a larger uncertainty. The derived curve of Slack [2] is also shown in figure 10; this represents essentially all of the thermal conductivity values reported for platinum prior to 1962 with the exception of the data of Krishnan and Jain [10].

The previously unreported data of $\mathrm{W}$ atson and Flynn [32] shown in figure 10 were made at NBS on the bar from which the specimen for the present in-
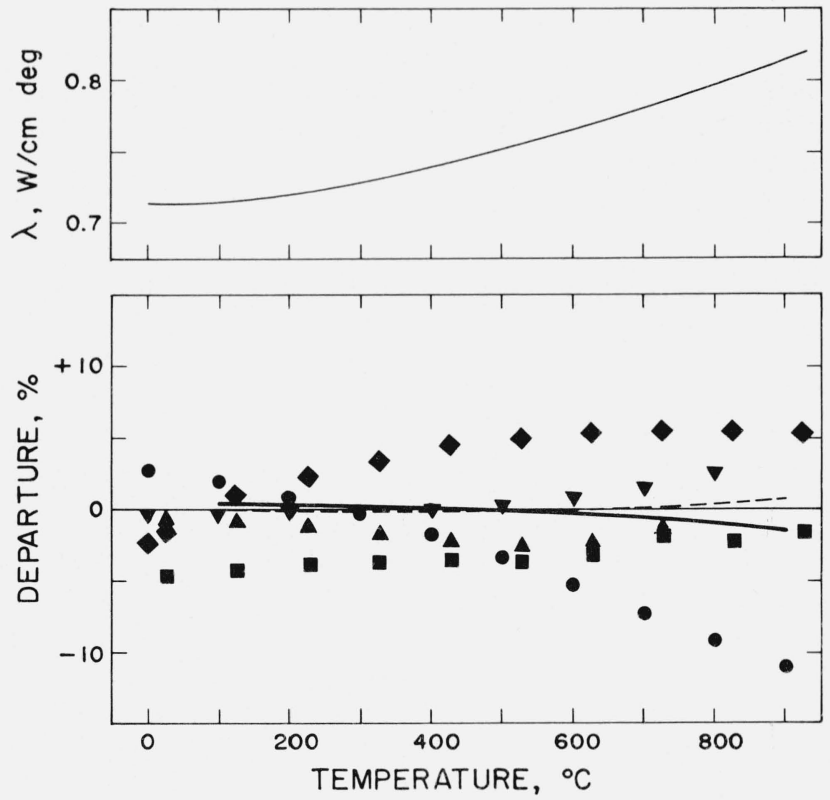

FIgURE 10. Thermal conductivity of platinum: comparison of previous data with the results of the present investigation.

The curve in the upper drawing and the baseline in the lower drawing correspond to a weighted average of the two sets of data from the present investigation with the data from the longitudinal heat flow method being given twice the weight of the data from the electrical method.

Present investigation - longitudinal heat flow method.

Present investigation-electrical method.

V Watson and Flynn [32]-same sample as that used in the present investigation.

- The curve of Slack |2|.

Powell and Tye [1].

Laubitz and van der Meer [30]

Martin, Sidles, and Danielson [37], the values shown correspond to their sample D. 


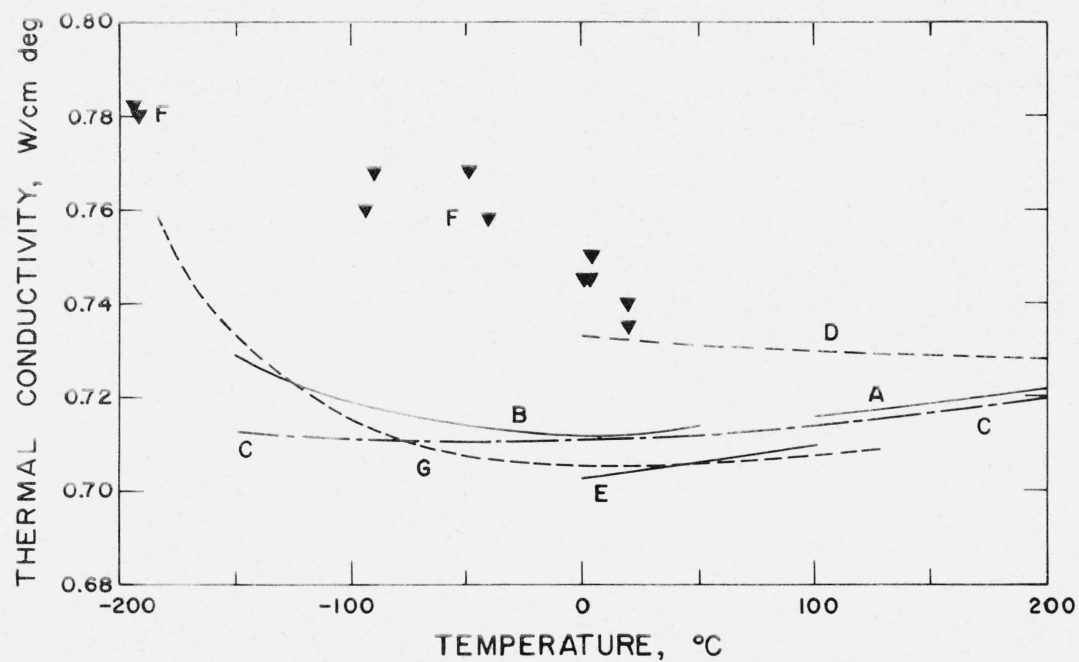

FIGURE 11. Thermal conductivity of platinum: comparison between existing low temperature data and those of the present investigation.

A. Present investigation: the curve shown is that obtained by the longitudinal heat flow method.

B. Halpern and Flynn |33|: measurements made on a portion of the sample used for the present investigation.

C. Watson and Flynn |32|: measurements made on a portion of the sample used for the present investigation.

D. Powell and Tye $[1]$

E. Bode $[281$

F. Powell, Tye, and Woodman |39|: measurements made on one of the samples of Powell and Tye $[1 \mid$

G. Moore and McElroy [40]: measurements made on one of the samples of Powell and Tye [1].

vestigation was later machined. Watson and Flynn made their measurements in air in a longitudinal heat flow apparatus which has been described by Watson and Robinson [34] and by Ginnings [35].

Several recent sets of thermal conductivity values for platinum at lower temperatures are displayed in figure 11. The data of Powell and Tye [1], curve D, were also shown in figure 10. The data of Bode [38], curve $\mathrm{E}$, were obtained using a longitudinal heat flow method; Bode stated that he considered his values to be accurate to within 0.5 percent. Since the present investigation was begun, Powell, Tye, and Woodman [39], curve F, have used a longitudinal heat flow method to make low temperature thermal conductivity measurements on one of the samples of Powell and Tye. Also during this time, Moore and McElroy [40], curve $G$, have made thermal conductivity measurements on the same sample which Powell, Tye, and Woodman [39] used for their investigation. In the temperature range shown in figure 11 , the thermal conduc-

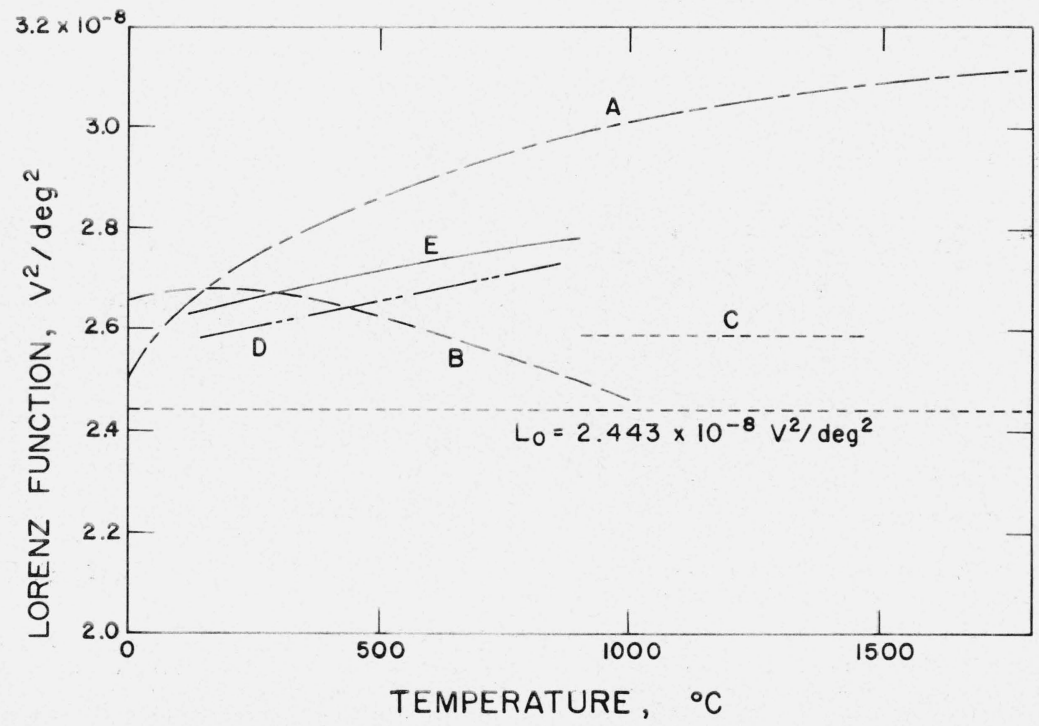

FIGURE 12. Lorenz function for platinum: comparison between existing data and

A. Slack $|2|$ those of the present investigation.

B. Powell and Tye 11

C. Wheeler $|36|$.

D. Martin. Sidles. and Danielson |37|: the values shown correspond to their sample D

E. Present investigation: the curve shown was computed from the thermal conductivity values obtained by the longitudinal heat flow methed. 
tivity of platinum could be affected by small differences in purity and this may account for some of the differences shown. However, the measurements of Powell, Tye, and Woodman [39] and those of Moore and McElroy [40] were carried out on the same sample; hence the differences between the results of these investigators must be presumed to be due to. experimental errors.

Additional references to previous measurements of the thermal conductivity of platinum are given by Powell, Ho, and Liley [8]. Ciszek [61] has recently reported some high temperature thermal diffusivity measurements for platinum.

Values obtained for the Lorenz function of platinum are compared with those of other investigators in figure 12. The present measurements indicate a Lorenz function increasing above the theoretical value as the temperature increases. Laubitz and van der Meer [30] point out that such behavior of the Lorenz function can be understood qualitatively if one assumes a low Fermi energy for platinum.

\section{Conclusions}

The good agreement among the thermal conductivity values obtained for platinum by two different methods in the present investigation and by an independent measurement by Watson and Flynn [32] lend considerable weight to these results. The values indicate that the thermal conductivity of platinum increases with temperature as found by Laubitz and van der Meer [30] rather than being essentially independent of temperature as found by Powell and Tye [1]. However, there remains the possibility that there is a real difference between the samples of Powell and Tye [1] and those of other investigators. In order to explore this possibility, measurements should be made at high temperatures in another laboratory on one of the actual samples of Powell and Tye. Steps are being taken to see if this can be done.

The results of the present investigation indicate that electrical methods of measuring thermal conductivity can yield equivalent results to those obtained by the more conventional nonelectrical methods, at least for the conditions of this investigation. This can be interpreted as indicating that the thermal conductivity of platinum does not depend significantly on electric current densities in the range less than $10^{4} \mathrm{~A} / \mathrm{cm}^{2}$.

Before platinum can be established as a thermal conductivity reference standard, additional measurements by the same method on samples of differing purity are indicated. It is intended to repeat the measurements described in this paper on a sample of platinum of higher purity than that used in the present investigation.

We appreciate the advice and assistance provided by Henry G. Albert and A. V. Lincoln, both of Engelhard Industries, Inc. We thank Henry E. Robinson, Chief, Environmental Engineering Section, NBS, and
Adjunct Professor of Engineering, The George Washington University, for his advice and support. The intricate and difficult machining required for this project was done by Raymond Chidester. Much good advice in matters of fabrication came from John Hettenhouser.

\section{Appendix A. Evaluation of $\boldsymbol{D}\left(z_{1}, z_{2}\right)$}

In this appendix, the factor $D\left(z_{1}, z_{2}\right)$ is evaluated. This factor was needed to correct for heat exchange between the specimen and the surrounding insulation in the longitudinal heat flow method.

In order to evaluate $D\left(z_{1}, z_{2}\right)$ one must know the temperature dependence of the thermal conductivity of the powder insulation as well as the radial temperature gradient at the surface of the specimen. The thermal conductivity of the insulation was assumed to be a linear function of temperature;

$$
\kappa=\kappa_{0}\left(1+\delta_{0} \theta\right)
$$

where $\kappa_{0}$ and $\delta_{0}$ are evaluated at $\theta=0, \delta$ being the temperature coefficient of the thermal conductivity of the insulation. Then, from (14)

$$
\xi=\theta+\frac{\delta_{0}}{2} \theta^{2}
$$

The radial temperature gradient at the surface of the specimen was determined by analysis of the hollow cylinder of powder insulation between the specimen and the guard with known temperature distributions at its boundaries. At the surface of the specimen, $r=a$, the potential distribution was represented by

$$
(\xi)_{r=\emptyset}=g_{0}+\left(g_{\omega}-g_{0}\right) \frac{z}{\omega}+\sum_{n=1}^{\infty} A_{n} \sin \frac{n \pi z}{\omega},
$$

and at the inner surface of the guard, $r=b$, the potential distribution was represented by

$$
(\xi)_{r=b}=h_{0}+\left(h_{\omega}-h_{0}\right) \frac{z}{\omega}+\sum_{n=1}^{\infty} B_{n} \sin \frac{n \pi z}{\omega},
$$

where $\xi(r, z)$ has the values $\xi(a, 0)=g_{0}, \xi(a, \omega)=g_{\omega}$, $\xi(b, 0)=h_{0}, \xi(b, \omega)=h_{\omega}$, at the ends of the region, $z=0$ and $z=\omega$, which correspond to the outermost thermocouples on the guard. At these ends the radial temperature distribution in the powder insulation was assumed to be logarithmic:

$$
\begin{aligned}
& (\xi)_{z=0}=g_{0}+\left(h_{0}-g_{0}\right) \frac{\ln r / a}{\ln b / a} \\
& (\xi)_{z=\omega}=g_{\omega}+\left(h_{\omega}-g_{\omega}\right) \frac{\ln r / a}{\ln b / a} .
\end{aligned}
$$

The Fourier coefficients $A_{n}$ and $B_{n}$ in $(\mathrm{A}-3)$ and 
(A-4) were determined from the measured temperature distributions along the specimen assembly and the guard cylinder. In the gradient region of the specimen, and in the upper and lower specimen extensions, the observed temperatures and thermocouple locations (corrected for thermal expansion) were used to derive quadratic equations giving $\theta$ versus $z$, where $\theta$ was measured relative to the temperature at the center of the gradient region of the specimen. In the neck region, which was nearly isothermal at all times, a linear equation was used. The three quadratics in $\theta$ transformed to quartics in $\xi$ and the linear equation in $\theta$ transformed to a quadratic in $\xi$ with application of $(\mathrm{A}-2)$. In the intervening heater regions, smoothing cubics [27] were used which provided continuity of temperature and longitudinal temperature gradients. Thus the $\xi$-distribution along the specimen was described by seven smoothly joined polynomials: quartic (lower extension), smoothing cubic (lower extension heater), quartic (gradient region of specimen), smoothing cubic (specimen heater), quadratic (neck region of specimen), smoothing cubic (upper extension heater), quadratic (upper extension). Equating this set of polynomials to the right-hand side of $(A-3)$ and making use of orthogonality enabled calculation of the $A_{n}$ 's. A similar set of polynomials was used to represent the $\xi$-distribution along the guard, from which the $B_{n}$ 's were calculated. It would serve no useful purpose to explicitly display the expressions for $A_{n}$ or $B_{n}$ in this paper; they are quite lengthy and rather complex.

With the boundary conditions $(\mathrm{A}-3,(\mathrm{~A}-4),(\mathrm{A}-5)$, and (A-6) the potential, $\xi$, at any point in the powder insulation is given by

$$
\begin{aligned}
\xi=\left[g_{0}+\left(h_{0}-g_{0}\right) \frac{\ln r / a}{\ln b / a}\left(1-\frac{z}{\omega}\right)+\left[g_{\omega}+\left(h_{\omega}-g_{\omega}\right) \frac{\ln r / a}{\ln b / a}\right] \frac{z}{\omega}\right. \\
+\sum_{n=1}^{\infty} \frac{A_{n} F_{0}(n \pi r / \omega ; n \pi b / \omega)-B_{n} F_{0}(n \pi r / \omega ; n \pi a / \omega)}{F_{0}(n \pi a / \omega ; n \pi b / \omega)} \sin \frac{n \pi z}{\omega},
\end{aligned}
$$

where

$$
\begin{aligned}
F_{0}(x, y) & \equiv I_{0}(x) K_{0}(y)-K_{0}(x) I_{0}(y), \\
I_{m} & =\text { modified Bessel function of first kind and order } m, \\
K_{m} & =\text { modified Bessel function of second kind and order } m .
\end{aligned}
$$

Substitution of (A-7) into (16) yields $D\left(z_{1}, z_{2}\right)$ :

$$
\begin{aligned}
D\left(z_{1}, z_{2}\right)=2 \pi a\left[\left\{\left(h_{0}-g_{0}\right)\left(z_{2}-z_{1}\right)+\right.\right. & \left.\left(h_{\omega}-h_{0}-g_{\omega}+g_{0}\right) \frac{z_{2}^{2}-z_{1}^{2}}{2 \omega}\right\} \frac{1}{a \ln b / a} \\
& \left.-\sum_{n=1}^{\infty} \frac{A_{n} F_{1}(n \pi a / \omega ; n \pi b / \omega)-(\omega / n \pi a) B_{n}}{F_{0}(n \pi a / \omega ; n \pi b / \omega)}\left(\cos \frac{n \pi z_{2}}{\omega}-\cos \frac{n \pi z_{1}}{\omega}\right)\right],
\end{aligned}
$$

where $\quad F_{1}(x, y) \equiv I_{1}(x) K_{0}(y)+K_{1}(x) I_{0}(y)$.

\section{Appendix B. Evaluation of Heat Loss from Heater Jumpers}

As discussed in section $4.2 \mathrm{~b}$, the "jumpers" shown in figure 3 were heated by conduction from the helical heater elements to a temperature somewhat above that of the adjacent portion of the specimen. Since the smoothing functions [27] used to represent the temperature distribution along the specimen did not allow for this local hot region, an uncorrected-for heat loss from the jumpers into the powder insulation must have occurred. The purpose of this appendix is to estimate the possible magnitude of this heat loss.

We will assume that the five hot jumpers can be represented by equivalent hot regions at the convex surface, $r=a$, of the specimen. By integrating over the angular temperature distribution near the longitudinal position of the heater, we can obtain an effective average longitudinal temperature distribution which can be used to estimate the heat loss from the jumpers. We assume that, for a gradient test, the effective longitudinal temperature distribution was as shown in the curve labeled $g^{\prime}(z)$, in figure 13 . In our analysis, it was assumed that the temperature distribution was as shown in the curve labeled $g(z)$ in figure 13 . The difference between the effective longitudinal temperature distribution, $g^{\prime}(z)$, and the assumed temperature distribution, $g(z)$, is shown in the curve labeled $g^{\prime \prime}(z)$ in figure 13.

If we go through an analysis similar to that in ap- 

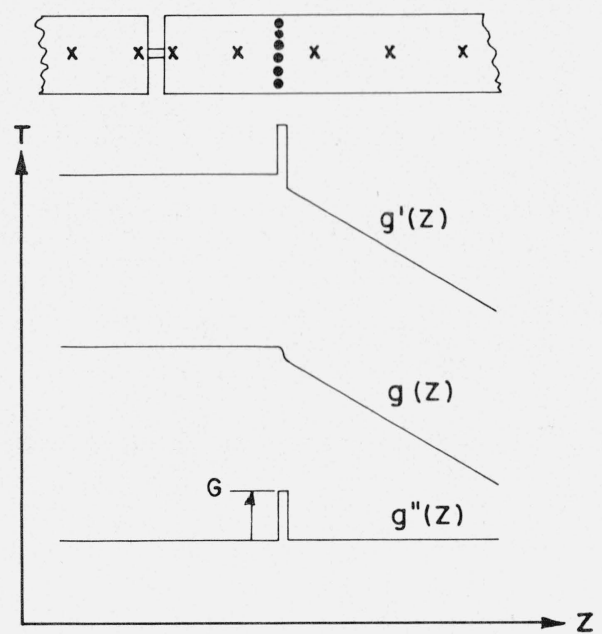

FigURE 13. Longitudinal temperature distribution in the vicinity of the specimen heater.

The three different curves are identified in the text.

pendix A, but using $g^{\prime}(z)$ rather than $g(z)$ to represent the longitudinal temperature distribution along the specimen, we obtain

$$
D^{\prime}\left(z_{1}, z_{2}\right)=D\left(z_{1}, z_{2}\right)+D^{\prime \prime}\left(z_{1}, z_{2}\right),
$$

where $D^{\prime}\left(z_{1}, z_{2}\right)$ corresponds to $g^{\prime}(z), D\left(z_{1}, z_{2}\right)$ is given by $(\mathrm{A}-8)$, and

$$
\begin{array}{r}
D^{\prime \prime}\left(z_{1}, z_{2}\right)=-2 \pi a \sum_{n=1}^{\infty} A_{n}^{\prime \prime} \frac{F_{1}(n \pi a / \omega: n \pi b / \omega)}{F_{0}(n \pi a / \omega ; n \pi b / \omega)}\left(\cos \frac{n \pi z_{2}}{\omega}\right. \\
\left.-\cos \frac{n \pi z_{1}}{\omega}\right), \quad(\mathrm{B}-2)
\end{array}
$$

where the Fourier coefficients $A_{n}^{\prime \prime}$ are defined by

$$
A_{n}^{\prime \prime}=\frac{2}{\omega} \int_{0}^{\omega} g^{\prime \prime}(z) \sin \frac{n \pi z}{\omega} d z
$$

Let us assume that $g^{\prime \prime}(z)$ can be represented by

$$
\left.\begin{array}{ll}
g^{\prime \prime}(z)=G, & \ell-\epsilon<z<\ell+\epsilon \\
g^{\prime \prime}(z)=0, & \text { elsewhere }
\end{array}\right\}
$$

where $\ell$ is the location of the center plane of the heater which has a thickness of $2 \epsilon$. Substitution of (B-4) into $(\mathrm{B}-3)$ yields, after integration,

$$
A_{n}^{\prime \prime}=\frac{4 G}{n \pi} \sin \frac{n \pi \ell}{\omega} \sin \frac{n \pi \epsilon}{\omega} .
$$

Using (B-5) for $A_{n}^{\prime \prime}$, evaluation of (B-2) for the geometry of our apparatus yields $D^{\prime \prime}\left(z_{1}, z_{2}\right)=1.2 \mathrm{G}$ (deg $\mathrm{cm}$ ).

An upper limit for the temperature of the jumpers was provided by the average temperature of the heater winding, which was determined using the heater as a resistance thermometer. The jumpers shown in figure 3 occupied less than 25 percent of the perimeter of the specimen at the midplane of the specimen heater. Using this information an upper limit for $G$ was determined for each of the tests in table 1 . Using this in conjunction with the measured values of $\kappa$ and the value for $D^{\prime \prime}\left(z_{1}, z_{2}\right)$ obtained above, the maximum error due to the uncorrected-for heat loss from the jumpers was computed to increase from 0.2 percent at $100{ }^{\circ} \mathrm{C}$ to 0.5 percent at $900{ }^{\circ} \mathrm{C}$.

\section{Appendix C. Theory of the Electrical Method}

Although the theory of electrical methods of measuring thermal conductivity had been developed in the literature, there was no single reference that adequately covered the subject. In the present investigation, it was found necessary to digest a rather large number of papers in order to arrive at an understanding of the validity of the expressions used for computing the thermal conductivity values. It is hoped that the fairly unified treatment given in this appendix will be useful to future workers in this area.

In the electrical method the specimen supports an electrical potential gradient, as well as a temperature gradient, and the corresponding thermoelectric effects must be analyzed. This is done most conveniently by the methods of irreversible thermodynamics, applying the Onsager Reciprocal Relations [44-54]. The application of the relations to steady-state processes involves an approximation; but as Callen [44] points out, it is an excellent approximation and is completely justifiable in this case.

We define a set of current densities $\mathbf{J}_{i}$ :

$$
\mathbf{J}_{i}=\sum_{j} L_{i j} \mathbf{X}_{j},
$$

where $\mathbf{X}_{j}$ are the "conjugate forces," such that

$$
R(S)=\sum_{i} \mathbf{J}_{i} \cdot \mathbf{X}_{i},
$$

where $R(S)$ is the rate of production of entropy in the system. Then the Onsager Reciprocal Theorem $[53,54 \mid$ states that

$$
L_{i j}=L_{j i}
$$

in the absence of a magnetic field. The rate of entropy production $R(S)$ is uniquely defined by the system under consideration, but since $R(S)$ can be split into a sum of products in many ways, one is left with a choice of current densities and conjugate forces [45].

We define an electric current density $\mathbf{J}$, an energy current density $\mathbf{W}$, and an entropy current density $\mathbf{S}$, so that the divergence of each of these current densities is the rate of change per unit volume of the corresponding thermodynamic variable. With these 
definitions for the current densities we can write [44, eq 12]:

$$
T \mathbf{S}=\mathbf{W}-\frac{\mu}{e} \mathbf{J} .
$$

where $T$ is the absolute temperature, $\mu$ is the electrochemical potential, $e$ is the electronic charge and $\mathbf{J}$, the electric current density, is equal to the electron current density times the electronic charge. We are considering the electron current to be the only mass current. Mass transport and the associated entropy flows due to electromigration (preferential migration of ions in a solid when a direct current is passed through the solid) and due to the Soret effect (mass transport in a solid due to a temperature gradient) are not considered. The reader is referred to [41-43] for discussions of these two effects.

We are concerned with steady-state conditions for which:

$$
\begin{array}{ll}
\boldsymbol{\nabla} \cdot \mathbf{W}=0, & (\mathrm{C}-5) \\
\boldsymbol{\nabla} \cdot \mathbf{J}=0, & (\mathrm{C}-6) \\
\boldsymbol{\nabla} \cdot \mathbf{S}=R(S), & (\mathrm{C}-7)
\end{array}
$$

From $(\mathrm{C}-4)$ and $(\mathrm{C}-7)$ we can write

$$
R(S)=\mathbf{J} \cdot\left[-\frac{\mu}{e} \nabla\left(\frac{1}{T}\right)-\frac{1}{T} \nabla\left(\frac{\mu}{e}\right)\right]+\mathbf{W} \cdot \nabla\left(\frac{1}{T}\right) .
$$

Using the identity

$$
\nabla\left(\frac{1}{T}\right)=-\frac{1}{T^{2}} \nabla T,
$$

we can write the current densities in terms of the "conjugate forces":

$$
\begin{aligned}
& \mathbf{J}=L_{11}\left[\frac{\mu}{e T^{2}} \nabla T-\frac{1}{T} \nabla\left(\frac{\mu}{e}\right)\right]+L_{12}\left[-\frac{1}{T^{2}} \nabla T\right] \\
& \mathbf{W}=L_{12}\left[\frac{\mu}{e T^{2}} \nabla T-\frac{1}{T} \nabla\left(\frac{\mu}{e}\right)\right]+L_{22}\left[-\frac{1}{T^{2}} \nabla T\right] .
\end{aligned}
$$

The electrochemical potential $\mu$ is given by

$$
\mu=\zeta+e \phi
$$

where $\phi$ is the electrostatic potential, and $\zeta$ is the chemical potential, which in the case of a metal is simply the Fermi energy [55]. Since the Fermi energy is a function of temperature only, we can write

$$
\nabla\left(\frac{\mu}{e}\right)=\frac{1}{e} \frac{\partial \zeta}{\partial T} \nabla T+\nabla \phi
$$

We now proceed to evaluate the coefficients $L_{11}, L_{12}$, and $L_{22}$.

The electrical conductivity is defined under isothermal conditions (i.e., $\nabla T=0$ ) as

$$
\sigma=\left[\frac{-\mathbf{J}}{\nabla \phi}\right]_{\nabla T=0}=\left[\frac{-\mathbf{J}}{\nabla(\mu / e)}\right]_{\nabla T=0},
$$

since for $\boldsymbol{\nabla} T=0, \boldsymbol{\nabla}(\mu / e)=\boldsymbol{\nabla} \phi$. From $(\mathrm{C}-10)$ it follows that

$$
L_{11}=\sigma T .
$$

The absolute thermoelectric power is defined (see [56]) as

$$
S^{\mathrm{abs}}=\left[\frac{-\nabla(\mu / e)}{\nabla T}\right]_{\mathbf{J}=0} .
$$

and from $(\mathrm{C}-10)$ it follows that

$$
L_{12}=\sigma T\left[\frac{\mu}{e}+T S^{\mathrm{abs}}\right] .
$$

The thermal conductivity is defined as

$$
\lambda=\left[\frac{-\mathbf{Q}}{\nabla T}\right]_{\mathrm{J}=0}=\left[\frac{-\mathbf{W}}{\boldsymbol{\nabla} T}\right]_{\mathbf{J}=0},
$$

where $\mathbf{Q}$ is the heat current density, since when $\mathbf{J}=0, \mathbf{W}=\mathbf{Q}$.

From $(\mathrm{C}-10)$ and $(\mathrm{C}-11)$ we get

$$
L_{22}=\lambda T^{2}+\sigma T\left[\frac{\mu}{e}+T S^{\mathrm{abs}}\right]^{2} .
$$

Substituting for $L_{11}, L_{12}$, and $L_{22}$ in $(\mathrm{C}-10)$ and $(\mathrm{C}-11)$, we can write $\mathbf{J}$ and $\mathbf{W}$ in terms of the defined thermoelectric parameters:

$$
\begin{aligned}
\mathbf{J} & =-\sigma\left[\nabla\left(\frac{\mu}{e}\right)+S^{\mathrm{abs}} \nabla T\right] \\
\mathbb{W} & =\left[\frac{\mu}{e}+T S^{\mathrm{abs}}\right] \mathbf{J}-\lambda \nabla T .
\end{aligned}
$$

Taking the divergence of $\mathbf{W}$ and using $(\mathbf{C}-5)$ and $(\mathrm{C}-6)$,

$$
\boldsymbol{\nabla} \cdot \mathbf{W}=\mathbf{J} \cdot \boldsymbol{\nabla}\left(\mu / e+T S^{\mathrm{abs}}\right)-\boldsymbol{\nabla} \cdot \lambda \boldsymbol{\nabla} T=0 .
$$

Therefore

$$
\mathbf{J} \cdot\left[\boldsymbol{\nabla}(\mu / e)+T \nabla S^{\mathrm{abs}}+S^{\mathrm{abs}} \boldsymbol{\nabla} T\right]-\boldsymbol{\nabla} \cdot \lambda \boldsymbol{\nabla} T=0 .
$$


In a homogeneous and isotropic medium, the parameter $S^{\text {abs }}$ is a function of temperature only, and we can write

$$
\mathbf{J} \cdot\left[\boldsymbol{\nabla}(\mu / e)+\left(T \partial S^{\mathrm{abs}} / \partial T\right) \boldsymbol{\nabla} T+S^{\mathrm{abs}} \boldsymbol{\nabla} T\right]-\boldsymbol{\nabla} \cdot \lambda \boldsymbol{\nabla} T=0 .
$$

The coefficient $T \partial S^{\text {abs }} / \partial T$ is defined [44] as the Thomson coefficient $\tau$. From $(\mathrm{C}-20)$ and $(\mathrm{C}-24)$

$$
\mathbf{J} \cdot[-\mathbf{J} / \sigma+\tau \nabla T]-\nabla \cdot \lambda \boldsymbol{\nabla} T=0 .
$$

At this point, it is convenient to introduce a pseudopotential $\psi$ such that

$$
\mathbf{J}=-\sigma \nabla \psi
$$

and

$$
\nabla \psi=\nabla(\mu / e)+S^{\mathrm{abs}} \nabla T .
$$

Writing $(\mathrm{C}-25)$ in terms of $\psi$ we get

$$
\boldsymbol{\nabla} \cdot \lambda \boldsymbol{\nabla} T+\sigma \boldsymbol{\nabla} \psi \cdot \boldsymbol{\nabla} \psi+\sigma \tau \boldsymbol{\nabla} \psi \cdot \boldsymbol{\nabla} T=0 .
$$

Equation $(\mathrm{C}-28)$ can be considered as the generalized equation relating the temperature distribution and the pseudo-potential distribution in an isotropic homogeneous medium carrying an electric current. We now proceed to solve that equation.

The second term in $(\mathrm{C}-28)$ can be written as $\boldsymbol{\nabla} \cdot\left(\psi^{\prime} \sigma \nabla \boldsymbol{\nabla} \psi\right)$ since

$$
\begin{aligned}
& \boldsymbol{\nabla} \cdot\left(\psi_{\sigma} \boldsymbol{\nabla} \psi\right)=\psi \boldsymbol{\nabla} \cdot(\sigma \boldsymbol{\nabla} \psi)+\sigma \boldsymbol{\nabla} \psi \cdot \boldsymbol{\nabla} \psi \\
& =\sigma \boldsymbol{\nabla} \psi \cdot \boldsymbol{\nabla} \psi, \text { since } \boldsymbol{\nabla} \cdot \sigma \boldsymbol{\nabla} \psi=-\boldsymbol{\nabla} \cdot \mathbf{J}=0
\end{aligned}
$$

The third term in $(\mathbf{C}-28)$ can also be written in the form of a divergence, since

$$
\begin{array}{r}
\boldsymbol{\nabla} \cdot\left[\sigma\left(\int_{T^{*}}^{T} \tau d T\right) \boldsymbol{\nabla} \psi\right]=\sigma \boldsymbol{\nabla} \psi \cdot \boldsymbol{\nabla} \int_{T^{*}}^{T} \tau d T \\
+\left(\int_{T^{*}}^{T} \tau d T\right) \boldsymbol{\nabla} \cdot(\sigma \boldsymbol{\nabla} \psi) \\
=\sigma \boldsymbol{\nabla} \psi \cdot \boldsymbol{\nabla} \int_{T^{*}}^{T} \tau d T=\sigma \tau \boldsymbol{\nabla} \psi \cdot \boldsymbol{\nabla} T,
\end{array}
$$

where $T^{*}$ is any arbitrary fixed temperature.

Using these identities $(\mathrm{C}-28)$ can be written as

$$
\boldsymbol{\nabla} \cdot\left[\lambda \boldsymbol{\nabla} T+\sigma \psi \boldsymbol{\nabla} \psi+\sigma\left(\int_{T^{*}}^{T} \tau d T\right) \boldsymbol{\nabla} \psi\right]=0 .
$$

Integrating,

$\lambda \boldsymbol{\nabla} T+\sigma \psi \nabla \psi+\sigma\left(\int_{T^{*}}^{T} \tau d T\right) \boldsymbol{\nabla} \psi=\boldsymbol{\nabla} \xi+\mathbf{c}$, where $\xi$ is any potential satisfying the Laplacian $\nabla^{2} \xi=0$ and $\boldsymbol{c}$ is a vector constant. Since $\boldsymbol{\nabla} \cdot(\sigma \boldsymbol{\nabla} \psi)=0$ we can write

$$
\boldsymbol{\nabla} \xi=\psi_{0} \sigma \nabla \psi
$$

where $\psi_{0}$ is a constant which must satisfy the boundary conditions. Substituting for $\nabla \xi$ in $(\mathrm{C}-32)$, we get

$$
\lambda \boldsymbol{\nabla} T+\sigma\left(\psi-\psi_{0}\right) \boldsymbol{\nabla} \psi+(\sigma \nabla \psi) \int_{T^{*}}^{T} \tau d T=\mathbf{c} .
$$

If $\mathbf{c}=0$, it can be seen from $(\mathrm{C}-34)$ that $\boldsymbol{\nabla} T$ and $\boldsymbol{\nabla} \psi$ must be parallel at all points. This implies that if there is no electric current flow across a boundary, there can be no heat flow across that same boundary. Moreover, equipotential surfaces are also isothermal. More explicitly, the condition that $\mathbf{c}=0$ requires that all the heat generated in an electrically insulated conductor must flow out at the ends of the conductor, there being no heat losses from the sides. This condition can never actually be met in practice since there is no perfect or even near-perfect thermal insulator. However, by appropriate choice of geometry, as employed in the present experiments, heat losses can be made very small so that we can take $\mathbf{c}=0$ as a valid statement of the boundary condition. Equation $(\mathrm{C}-34)$ then reduces to

$$
\lambda \rho \nabla T+\left(\psi-\psi_{0}\right) \boldsymbol{\nabla} \psi+(\boldsymbol{\nabla} \psi) \int_{T^{*}}^{T} \tau d T=0,
$$

where $\rho$ is the electrical resistivity, $\rho=1 / \sigma$.

If there is a point in the medium where the temperature has a maximum value, $T_{m}$, the gradient $\nabla T$ is zero at that point. Further, if we let

$$
T^{*}=T_{m}
$$

the first and third terms in $(\mathrm{C}-35)$ are zero at $T=T_{m}$. Since there is a current flowing, $\sigma \boldsymbol{\nabla} \psi \neq 0$ and $(C-35)$ is satisfied only if $\psi-\psi_{0}=0$ at $T=T_{m}$. In other words

$$
\psi=\psi_{0} \text { at } T=T_{m},
$$

so that $\psi_{0}$ is the value of $\psi$ at the point of maximum temperature.

Integrating $(\mathrm{C}-35)$ along a line from one isothermal surface $S_{1}\left(T_{1}, \psi_{1}\right)$ to another isothermal surface $S_{2}\left(T_{2}, \psi_{2}\right)$ and substituting $T_{m}$ for $T^{*}$,

$$
\begin{aligned}
& \int_{S_{1}}^{S_{2}} \lambda \rho \nabla T \cdot d \mathbf{r}+\int_{S_{1}}^{S_{2}}\left(\psi-\psi_{0}\right) \nabla \psi \cdot d \mathbf{r} \\
&+\int_{S_{1}}^{S_{2}} \nabla \psi \cdot d \mathbf{r} \int_{T_{m}}^{T} \tau d T=0,
\end{aligned}
$$

where $\mathbf{r}$ is a position vector. Since $\nabla T \cdot d \mathbf{r}=d T$ and $\boldsymbol{\nabla} \psi \cdot d \mathbf{r}=d \psi$, we have

$$
\int_{T_{1}}^{T_{2}} \lambda \rho d T+\int_{\psi_{1}}^{\psi_{2}}\left(\psi-\psi_{0}\right) d \psi+\int_{\psi_{1}}^{\psi_{2}} d \psi \int_{T_{m}}^{T} \tau d T=0 .
$$




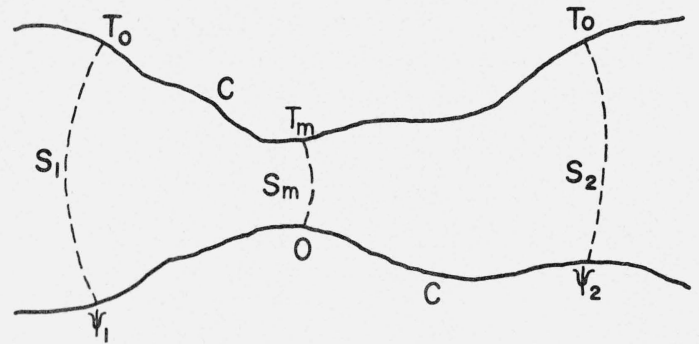

FigURE 14. A thermally and electrically insulated conductor of arbitrary geometry.

An arbitrary isotropic and homogeneous conductor is represented in figure 14 .

There is no electric current flow across the boundary $\mathrm{C}$ and the geometry is selected to make heat losses from $\mathrm{C}$ negligible so that the condition for $\mathbf{c}=0$ discussed above is satisfied. The isothermal surfaces $S_{1}$ and $S_{2}$ are taken to be at the same temperature, $T_{0}$, and the surface of maximum temperature is represented by $S_{m}$. In the absence of the Thomson effect, the surface of maximum temperature would bisect the reduced resistance between $S_{1}$ and $S_{2}$, the reduced resistance-a geometrical quantity-being the resistance of the medium for electrical conductivity of unity. However, the Thomson effect moves the surface of maximum temperature away from the symmetrical location, this effect being referred to as the "Thomson shift" [57]. It is analyzed in detail by Davidson [57] and discussed by Holm [58] and Llewellyn Jones [59]. It is convenient to define $\psi_{0}=0$ and consider the integral $(\mathrm{C}-39)$ from $S_{m}$ where $T=T_{m}$ and $\psi=0$ to any other surface $S$ where $\psi=\psi, T=T$. Rearranging we have

$$
\int_{0}^{\psi} \psi d \psi=\int_{T}^{T_{m}} \lambda \rho d T+\int_{0}^{\psi} d \psi \int_{T}^{T_{m}} \tau d T .
$$

It is convenient to write $(\mathrm{C}-40)$ in the following form:

$$
\psi^{2}-2 \epsilon \psi-F^{2}=0
$$

where $\quad F\left(T, T_{m}\right)=+\left\{2 \int_{T}^{T_{m}} \lambda \rho d T\right\}^{1 / 2}$

and

$$
\epsilon\left(T, T_{m}\right)=\frac{1}{\psi} \int_{0}^{\psi} d \psi \int_{T}^{T_{m}} \tau d T .
$$

Solving the quadratic equation $(\mathrm{C}-41)$, we get

$$
\psi=\epsilon \pm\left(\epsilon^{2}+F^{2}\right)^{1 / 2}=\epsilon \pm F\left(1+(\epsilon / F)^{2}\right)^{1 / 2} .
$$

The Thomson effect is relatively small so that the second-order term $(\epsilon / F)^{2}$ in $(\mathrm{C}-44)$ can be neglected. Then

$$
\psi=\epsilon \pm F,
$$

the plus and minus signs referring to the high and low potential sides of $S_{m}$ respectively.

Referring to $(\mathrm{C}-43)$ we see that although $T$ is a function of $\psi$, the $\operatorname{sign}$ of $\int_{T}^{T_{m}} \tau d T$ is independent of the sign of $\psi$ since $T_{m}$ is always greater than $T$. Consequently $\epsilon$ is, to the first order, an even function of $\psi$. having the same value at corresponding points on the high and low potential sides of $S_{m}$. At $S_{1}$ we have

$$
\psi_{1}=\epsilon\left(T_{0}, T_{m}\right)-F\left(T_{0}, T_{m}\right)
$$

and at $S_{2}$

$$
\psi_{2}=\epsilon\left(T_{0}, T_{m}\right)+F\left(T_{0}, T_{m}\right) .
$$

Therefore,

$$
\psi_{2}-\psi_{1}=2 F\left(T_{0}, T_{m}\right) .
$$

From $(\mathrm{C}-27)$ and $(\mathrm{C}-13)$ we have

$$
\boldsymbol{\nabla} \psi=\boldsymbol{\nabla} \phi+\frac{1}{e} \frac{\partial \zeta}{\partial T} \boldsymbol{\nabla} T+S^{\mathrm{abs}} \boldsymbol{\nabla} T .
$$

Integrating from $S_{1}$ to $S_{2}$.

$$
\psi_{2}-\psi_{1}=\phi_{2}-\phi_{1}+\frac{1}{e}\left(\zeta_{2}-\zeta_{1}\right)+\int_{T_{1}}^{T_{2}} S^{\text {abs }} d T .
$$

In an isotropic and homogeneous medium $\zeta$ and $S^{\text {abs }}$ are functions of temperature only. When the terminal temperatures are the same, as in the case we are considering; i.e., when $T_{1}=T_{2}=T_{0}$, we can write from $(\mathrm{C}-48)$ and $(\mathrm{C}-50)$

$$
\psi_{2}-\psi_{1}=\phi_{2}-\phi_{1}=V=2 F\left(T_{0}, T_{m}\right),
$$

where $V$ is the voltage drop between the surfaces $S_{1}$ and $S_{2}$. If the potential probes are not at the same temperature, a correction must be made as indicated in $(\mathrm{C}-50)$. Writing $F$ explicitly we finally get from $(\mathrm{C}-51)$ and $(\mathrm{C}-42)$ :

$$
\frac{V^{2}}{8}=\int_{T_{0}}^{T_{m}} \lambda \rho d T=\int_{0}^{\theta_{m}} \lambda \rho d \theta,
$$

where $\theta=T-T_{0}, \theta_{m}=T_{m}-T_{0}$.

We now proceed to relate the maximum temperature rise in a conductor to the measured resistance of the conductor. This problem has been discussed by Meissner [20] and by Holm [58].

Consider two geometrically identical conductors differing only in that one (real) conductor has a finite temperature-dependent thermal conductivity, $\lambda=\lambda(\theta)$, 
while the other (hypothetical) conductor has an infinite thermal conductivity. Both conductors are assumed to have the same temperature-dependent electrical resistivity, $\rho=\rho(\theta)$. We assume the lateral surface of each conductor to be insulated perfectly against the flow of both heat and electricity. Let each end of both conductors be in thermal equilibrium with a heat $\operatorname{sink}$ at a temperature $\theta=0$. If an electrical current is passed through the real conductor, there will be an accompanying temperature rise due to the heat generated by the passage of the current. This in turn will cause a change in the electrical resistance of the conductor. Since the hypothetical conductor is assumed to have an infinite thermal conductivity, the temperature throughout this conductor will be $\theta=0$, even in the presence of heat generation, and the electrical resistivity will have the constant value $\rho=\rho(0)=\rho_{0}$ at all points in the hypothetical conductor. We wish to consider the difference between the electrical resistances of these two conductors due to the fact that one of them (real) is heated to a higher temperature due to having only a finite thermal conductivity.

Let $\psi$ and $\theta$ be the potential and the temperature respectively in the real conductor and let $\psi_{0}$ and $\theta_{0}$ refer to the corresponding variables in the hypothetical conductor. If the same electrical current is passed through these two conductors, the temperature and potential distributions in the two conductors will differ due to the temperature-dependence of the properties in the real conductor and also due to the thermal expansion of this conductor. If $d \psi$ and $d \psi_{0}$ are the potential differences between corresponding equipotential surfaces in the two conductors, we can, from $(\mathrm{C}-26)$, derive the relation

$$
\frac{d \psi_{0}}{d \psi}=\frac{\rho_{0}}{\rho}\left(1+\gamma_{0} \theta\right)
$$

where $\gamma_{0}$ is the coefficient of linear thermal expansion at $\theta=0$. Neglecting terms arising from the Thomson effect, we have from $(\mathrm{C}-41)$,

$$
\psi= \pm F
$$

and from $(\mathrm{C}-35)$,

$$
\lambda \rho \frac{d \theta}{d \psi}=-\psi
$$

Combining the last three equations,

$$
d \psi_{0}= \pm \frac{\lambda \rho_{0}\left(1+\gamma_{0} \theta\right) d \theta}{F}
$$

Integrating,

$$
\psi_{0}=\int_{0}^{\theta_{m}} \frac{\lambda \rho_{0}\left(1+\gamma_{0} \theta\right) d \theta}{F} \cdot \quad(\mathrm{C}-57)
$$

Since both conductors are assumed to carry the same current,

$$
\frac{R_{0}}{R}=\frac{\psi_{0}}{\psi}
$$

and we have

$$
\frac{R_{0}}{R}=\frac{1}{F} \int_{0}^{\theta_{m}} \frac{\lambda \rho_{0}\left(1+\gamma_{0} \theta\right) d \theta}{F}
$$

where $R$ is the electrical resistance between two surfaces at temperature $\theta=0$ in the real conductor and $R_{0}$ is that between these surfaces in the hypothetical conductor having an infinite thermal conductivity.

\section{References}

[1] Powell, R. W. and Tye, R. P., The promise of platinum as a high temperature thermal conductivity reference material, Brit. J. Appl. Phys. 14, 662 (1963).

[2] Slack, G. A., Platinum as a thermal conductivity standard, J. Appl. Phys. 35, 339 (1964).

[3| Hill, J. S. and Albert, H. J., Loss of weight of platinum, rhodium, and palladium at high temperatures, Engelhard Industries, Inc. Technical Bulletin, IV, 59 (1963).

[4] Galagali, R. J., Change of platinum resistance by hydrogen, Brit. J. Appl. Phys. 15, 208 (1964).

[5] Stimson, H. F., The international temperature scale of 1948 , J. Res. NBS 42, 209 (1949) RP 1962.

[6] Stimson, H. F., International practical temperature scale of 1948, text revision of 1960, J. Res. NBS 65A (Phys. and Chem.), No. 3, 139 (1961).

[7| Evans, J. P. and Burns, G. W., A study of stability of high temperature platinum resistance thermometers, in Temperature, Its Measurement and Control in Science and Industry, 3, Part 1, p. 313 (Reinhold, 1962).

[8] Powell, R. W.. Ho, C. Y., and Liley, P. E.. Thermal conductivity of selected materials, NSRDS-NBS 8 (Nov. 25, 1966).

[9] O'Hagan, M. E., Measurements of the Thermal Conductivity and Electrical Resistivity of Platinum from 373 to $1373{ }^{\circ} \mathrm{K}$, Doctoral Dissertation, The George Washington University (Aug. 1966).

[10] Krishnan, K. S. and Jain, S. C., Determination of thermal conductivities at high temperatures, Brit. J. Appl. Phys. 5, 426 (1954).

[11] Powell, R. W., Tye, R. P., and Woodman, M. J., Thermal conductivities and electrical resistivities of the platinum metals, Platinum Metals Rev. 6, 138 (1962).

[12 Martin, J. J. and Sidles, P. H., Thermal diffusivity of platinum from 300 to $1300{ }^{\circ} \mathrm{K}$, Report No. IS-1018, contribution No. 1614 of the Ames Laboratory of the U.S. Atomic Energy Commission (1964).

[13] Holm, R. and Störmer, R., Messung der Wärmeleitfähigkeit einer Platinprobe ein Temperaturgebeit 19 bis $1020^{\circ} \mathrm{C}$, Wiss. Veroff. Siemens-Werk 9, 312 (1930). (An unpublished English translation for NBS was made by Joint Publications Research Service.)

[14] Hopkins, M. R., The thermal and electrical conductivities of metals at high temperatures, Z. Phys. 147, 148 (1957).

[15] Cutler, M., Snodgrass, H. R., Cheney, G. T., Appel, J., Mallon, C. E., and Meyer, C. H., Jr., Thermal conductivity of reactor materials, Final Report GS-1939, General Atomic Division, General Dynamics Corporation, San Diego (30 January 1961).

[16] Wichers, E., The History of Pt 27, in Temperature, Its Measurement and Control in Science and Industry, 3, Part 1, p. 259 (Reinhold, 1962).

[17] Berry, R. J., Relationship between the real and ideal resistivity of platinum. Canad. J. Phys. 41, 946 (1963).

[18] Corruccini, R. J., Annealing of platinum for thermometry, J. Res. NBS 47, 94 (1951) RP2232. 
[19] Kirby, R. K., NBS, private communication (Dec. 1965).

[20] Meissner, W., Thermische und elektrische Leitfähigkeit einiger Metalle zwischen $20^{\circ}$ und $373^{\circ}$ abs., Ann. Phys. 47, 1001 (1915).

[21] McFee, R., Optimum input leads for cryogenic apparatus, Rev. Sci. Instr. 30, 98 (1959).

[22] Neighbor, J. E., Leads power in calorimetry, Rev. Sci. Instr. 37 , 497 (1966)

[23] Mallon, R. G., Optimum electrical leads of aluminum and sodium for cryogenic apparatus, Rev. Sci. Instr. 33, 564 (1962).

[24] Sobol, H. and McNicol, J. F., Evaporation of Helium I due to current-carrying leads, Rev. Sci. Instr. 33, 473 (1962).

[25] Stein, R. P., A solution of the steady linear heat-flow equation with heat generation and conductivity an arbitrary function of temperature, J. Appl. Mech. 26, 685 (1959).

[26] Ginnings, D. C. and West, E. D., Heater lead problem in calorimetry, Rev. Sci. Instr. 35, 965 (1964).

[27] Peavy, B. A., Determination and smoothing of Fourier coefficients representing sectionally discontinuous functions on a finite surface, J. Res. NBS 71C (Engr. and Instr.) No. 2, 93 (1967).

[28] Powell, R. W., Thermophysical Properties Research Center, private communication to D. R. Flynn (Oct. 1966).

[29] Evans, J. P., NBS, private communication (Aug. 1966).

[30] Laubitz, M. J. and van der Meer, M. P., The thermal conductivity of platinum between 300 and $1000^{\circ} \mathrm{K}$, Canad. J. Phys. 44, 3173 (1966).

[31] Roeser, Wm. F., in American Institute of Physics Handbook, Second Edition, p. 4-13 (McGraw-Hill Book Co., 1963). The values given in this reference have been adjusted to correspond to temperatures expressed on the International Practical Temperature Scale of 1948. The original reference is to the work of W. F. Roeser as given in Temperature, Its Measurement and Control in Science and Industry, p. 1312 (Reinhold, 1941).

[32] Watson, T. W. and Flynn, D. R., NBS, private communication (Jan. 1966).

[33] Halpern, Carl and Flynn, D. R., NBS, private communication (Aug. 1966).

[34] Watson, T. W. and Robinson, H. E., Thermal conductivity of some commercial iron-nickel alloys, Trans. ASME J. Heat Transfer 83C, 403 (1961).

[35] Ginnings, D. C., Standards of heat capacity and thermal conductivity, in Thermoelectricity, edited by Paul H. Egli, p. 320 (Wiley, 1960).

[36] Wheeler, M. J., Thermal diffusivity at incandescent temperatures by a modulated electron beam technique, Brit. J. Appl. Phys. 16, 365 (1965).

[37] Martin, J. J., Sidles, P. H., and Danielson, G. C., Thermal diffusivity of platinum, Report No. IS-1261, contribution No. 1810 of the Ames Laboratory of the U.S. Atomic Energy Commission.

[38] Bode, K-H, Messung der Wärmeleitfähigkeit von reinem Platin zwischen $0{ }^{\circ} \mathrm{C}$ und $100^{\circ} \mathrm{C}$, PTB Mitteilungen Nr. 5, 416 (1964).
[39] Powell, R. W., Tye, R. P., and Woodman, Margaret J., The thermal conductivity and electrical resistivity of polycrystalline metals of the platinum group and of single crystals of ruthenium, J. Less-Common Metals 12, 1 (1967).

[40] Moore, J. P., and McElroy, D. L., Oak Ridge National Laboratory, private communication (Mar. 1967).

[41] Huntington, H. B., and Ho, S. C., Electromigration in metals, J. Phys. Soc. Japan 18, Supplement II, 202 (1963)

[42] Ho, S. C., Hekenkamp, T. and Huntington, H. B., AEC Document Code No. RPI-1044-1, Contract HT(30-1)-1044 (Apr. 1, 1964).

[43] O'Boyle, D., Observations of electromigration and the Soret effect in tungsten, J. Appl. Phys. 36, 2849 (1965).

[44] Callen, H. B., The application of Onsager's reciprocal relations to thermoelectric, thermomagnetic, and galvanomagnetic effects, Phys. Rev. 73, 1349 (1948).

[45] De Groot, S. R., Thermodynamics of Irreversible Processes (Interscience, 1951).

[46] Domenicali, C. A., Irreversible thermodynamics of thermoelectric effects of inhomogeneous, anisotropic media, Phys. Rev. 92,877 (1953).

[47] Domenicali, C. A., Irreversible thermodynamics of thermoelectricity, Rev. Mod. Phys. 26, 237 (1954).

[48] Domenicali, C. A. Stationary temperature distribution in an electrically heated conductor, J. Appl. Phys. 25, 1310 (1954).

[49] Leech. J. W.. Irreversible thermodynamics and kinetic theory in the derivation of thermoelectric relations, Canad. J. Phys. 37, 1044 (1959).

[50] Ziman, J. M., Electrons and Phonons (Clarendon Press, Oxford, 1960).

[51] Beaumont, C. F. A., Connection between macroscopic and microscopic transport phenomena in solid conductors, Am. J. Phys. 33, 547 (1965).

[52] El-Saden, M. R., Theory of nonequilibrium thermodynamics with application to the transport processes in a solid, Trans. ASME, J. Heat Transfer, Paper No. 65-HT-1 (1965).

[53] Onsager, L., Reciprocal relations in irreversible processes, Part I, Phys. Rev. 37, 405 (1931).

[54] Onsager, L., Reciprocal relations in irreversible processes, Part II, Phys. Rev. 38, 2265 (1931).

[55] Callen, H. B., Thermoelectric and thermomagnetic effects in electrochemical constants, NBS Circular 524, 141 (1953).

[56] MacDonald, D. K. C., Thermoelectricity-An Introduction to the Principles (Wiley, 1962).

[57] Davidson, P. M., The theory of the Thomson effect in electrical contacts, Proc. Inst. Elec. Engrs. 96, Part 1, 293 (1949).

[58] Holm, R., Electric Contacts: Theory and Application, 4th ed. (Springer-Verlag, 1967).

[59] Llewellyn Jones, F., The Physics of Electrical Contacts (University Press, Oxford, 1957).

[60] Martin, J. J., Sidles, P. H., and Danielson, G. C., Thermal diffusivity of platinum from 300 to $1200^{\circ} \mathrm{K}$, J. Appl. Phys. 38, 3075 (1967)

[61] Ciszek, T. F., The Thermal Diffusivity and Electrical Resistivity of Platinum at Temperatures Above $1000^{\circ} \mathrm{K}$, Master's Thesis, Iowa State University (1966).

(Paper 71C4-258) 